\title{
CDK12 phosphorylates 4E-BP1 to enable mTORC1-dependent translation and mitotic genome stability
}

\author{
Seung H. Choi, ${ }^{1}$ Thomas F. Martinez, ${ }^{2}$ Seongjae Kim, ${ }^{3}$ Cynthia Donaldson, ${ }^{2}$ Maxim N. Shokhirev, ${ }^{4}$ \\ Alan Saghatelian, ${ }^{2}$ and Katherine A. Jones ${ }^{1}$ \\ ${ }^{1}$ Regulatory Biology Laboratory, ${ }^{2}$ Clayton Foundation Laboratory for Peptide Biology, ${ }^{3}$ Molecular Neurobiology Laboratory, \\ ${ }^{4}$ Razavi Newman Integrative Genomics and Bioinformatics Core, The Salk Institute for Biological Studies, La Jolla, California \\ 92037, USA
}

The RNA polymerase II (RNAPII) C-terminal domain kinase, CDK12, regulates genome stability, expression of DNA repair genes, and cancer cell resistance to chemotherapy and immunotherapy. In addition to its role in mRNA biosynthesis of DNA repair genes, we show here that CDK12 phosphorylates the mRNA $5^{\prime}$ cap-binding repressor, 4E-BP1, to promote translation of mTORC1-dependent mRNAs. In particular, we found that phosphorylation of 4E-BP1 by mTORC1 (T37 and T46) facilitates subsequent CDK12 phosphorylation at two Ser-Pro sites (S65 and T70) that control the exchange of 4E-BP1 with eIF4G at the $5^{\prime}$ cap of CHK1 and other target mRNAs. RNA immunoprecipitation coupled with deep sequencing (RIP-seq) revealed that CDK12 regulates release of 4E-BP1, and binding of eIF4G, to many mTORC1 target mRNAs, including those needed for MYC transformation. Genome-wide ribosome profiling (Ribo-seq) further identified specific CDK12 "translation-only" target mRNAs, including many mTORC1 target mRNAs as well as many subunits of mitotic and centromere/ centrosome complexes. Accordingly, confocal imaging analyses revealed severe chromosome misalignment, bridging, and segregation defects in cells deprived of CDK12 or CCNK. We conclude that the nuclear RNAPIICTD kinase CDK12 cooperates with mTORC1, and controls a specialized translation network that is essential for mitotic chromosome stability.

[Keywords: CDK12; RNAPII CTD kinase; 4E-BP1; translation; mTORC1; chromosome misalignment; genome stability] Supplemental material is available for this article.

Received November 14, 2018; revised version accepted January 22, 2019.

The nuclear cyclin-dependent kinases CDK7, CDK8, CDK9, and CDK12 function to integrate transcription with changes in phosphorylation of the RNA polymerase II (RNAPII) C-terminal domain (CTD) heptad repeats $\left(\mathrm{Y}_{1} \mathrm{~S}_{2} \mathrm{P}_{3} \mathrm{~T}_{4} \mathrm{~S}_{5} \mathrm{P}_{6} \mathrm{~S}_{7}\right)$ throughout the transcription cycle (Eick and Geyer 2013; Jonkers and Lis 2015; Harlen and Churchman 2017). Phosphorylation of the RNAPII CTD at the Ser-5 position by CDK7 is linked to promoter-proximal transcriptional pausing, and declines during the transition to active elongation, accompanied by an increase in Ser-2 phosphorylation mediated by CDK9 and CDK12 (Bartkowiak et al. 2010; Blazek et al. 2011; Cheng et al. 2012). Through phosphorylation of RNAPII and associated transcription factors, the nuclear RNAPII CTD kinases coordinate multiple cotranscriptional events important for gene expression, including mRNA splicing and surveillance, termination/cleavage, and export of nascent mRNAs (Bowman and Kelly 2014; Davidson

Corresponding author: jones@salk.edu

Article published online ahead of print. Article and publication date are online at http://www.genesdev.org/cgi/doi/10.1101/gad.322339.118. et al. 2014; Greenleaf 2018). However, it is unclear whether or how the metazoan RNAPII-CTD kinases could also affect more distal steps in gene expression, such as the translation efficiency of nascent mRNAs in the cytoplasm.

CDK12 plays a unique role among the CTD kinases in regulating genome stability and cancer cell drug resistance (Blazek et al. 2011; Joshi et al. 2014). Levels of CDK12 and its partner cyclin, Cyclin K (CCNK), are unaffected by the cell cycle, but are frequently elevated in proliferating stem cells and cancer cells. CDK12 affects the steady state mRNA levels of a relatively small set of genes, many of which, such as BRCA1 and ATR, are needed for DNA repair and homologous recombination (Blazek et al. 2011; Joshi et al. 2014; Liang et al. 2015). Other CDK12 targets include the c-FOS gene (Eifler et al.

(C) 2019 Choi et al. This article is distributed exclusively by Cold Spring Harbor Laboratory Press for the first six months after the full-issue publication date (see http://genesdev.cshlp.org/site/misc/terms.xhtml). After six months, it is available under a Creative Commons License (Attribution-NonCommercial 4.0 International), as described at http://creativecommons.org/licenses/by-nc/4.0/. 
2015), NRF2 target genes induced by oxidative stress (Li et al. 2016b), superenhancer linked oncogenes (Mertins et al. 2016), and genes critical for early embryonic development (Juan et al. 2016) and embryonic stem cell self-renewal (Dai et al. 2012). CTD-Ser2 phosphorylation by CDK12 has been shown to facilitate the loading of mRNA splicing and polyadenylation factors to RNAPII at the $3^{\prime}$ end of target genes (Hsin and Manley 2012; Davidson et al. 2014). Most interestingly, CDK12 profoundly suppresses intronic polyadenylation at BRCA1 and other target mRNAs (Dubbury et al. 2018). Consequently, loss or inactivation of CDK12 in cancer leads to the formation of truncated mRNAs, which may be unstable or encode aberrant proteins. In addition to the RNAPII CTD, CDK12 can phosphorylate and inactivate Cyclin E to stimulate the assembly of prereplicative DNA complexes (Lei et al. 2018).

Consistent with its role in genome stability, loss or mutation of CDK12 is associated with progression and metastasis of a subset of serous ovarian, breast, and prostate cancers (Ekumi et al. 2015; Popova et al. 2016; Menghi et al. 2018; Viswanathan et al. 2018). Inactivation of CDK12 strongly sensitizes cancer cells to undergo apoptosis in response to DNA damage agents and PARP1/2 inhibitors (Bajrami et al. 2014; Joshi et al. 2014; Ekumi et al. 2015). In addition, CDK12 is overexpressed in certain other cancers, including many HER2-positive breast cancers and a subset of ER-positive breast and prostate cancers (Mertins et al. 2016). Consequently, small-molecule CDK12 inhibitors are of great interest for use as targeted therapy for a variety of solid tumors (Mertins et al. 2016). Moreover, the subset of metastatic prostate cancers that lack CDK12 is also highly immunogenic (Wu et al. 2018), suggesting that CDK12 inhibition might also sensitize tumors to checkpoint inhibitor-based immunotherapies.

Here we report that, in addition to its role is mRNA biosynthesis, nuclear CDK12 cooperates with the mechanistic target of rapamycin (mTORC1) kinase to control the translation of a specific subset of mRNAs (Saxton and Sabatini 2017; Thoreen 2017). Using RNA-seq and ribosome profiling approaches, we show that CDK12 exclusively controls the translation of mRNAs encoding DNA repair factors, ribosome and translation factors, and many subunits of key centrosome, centromere, and kinetochore complexes. Surprisingly, we found that CDK12 affects the translation of these mRNAs directly by phosphorylating the translation repressor 4E-BP1 at two Ser-Pro sites (S65, T70) critical for its release from eIF4E at the cap of target mRNAs. These findings uncover a new mechanism through which an RNAPII-CTD kinase remodels the $5^{\prime}$ cap complex of nascent target mRNAs to facilitate gene-specific translation in the cytoplasm. Consistent with these findings, we show that cells deprived of CDK12 or CCNK display profound mitotic defects, including abnormal spindle poles, and chromosome segregation and bridging problems that trigger the spindle assembly checkpoint (SAC). We conclude that CDK12 controls a gene-specific translation network that includes many mTORC1-regulated genes and ensures the coordinate expression of many mitotic regulators.

\section{Results}

CDK12 regulates translation of the DNA damage response checkpoint kinase 1, CHK1

Based on the observation that CDK12 targets DNA repair genes (Blazek et al. 2011), we wondered whether it is also needed for the p53-regulated response to DNA damage (Matt and Hofmann 2016). Strikingly, depletion of either CDK12 or CCNK effectively blocked p53 induction in U2OS osteosarcoma cells treated with the DNA damage agent, etoposide (Fig. 1A). In contrast, basal p53 expression in the absence of etoposide was elevated in CDK12 knockdown cells, as has been observed previously (Dubbury et al. 2018). Protein half-life measurements carried out in the presence of etoposide (Supplemental Fig. S1A) revealed that $\mathrm{p} 53$ is less stable in CDK12-depleted cells $\left(t_{1 / 2}=\sim 16 \mathrm{~min}\right)$ than in cells expressing a control siRNA $\left(t_{1 / 2}=\sim 67 \mathrm{~min}\right)$. Consequently, we asked whether CDK12 regulates the expression of the CHK1 kinase or the HDM2 E3 ubiquitin ligase, which are known to control p53 stability. Interestingly, the levels of total and catalytically active (P-S317) CHK1 kinase were significantly reduced in cells deprived of either CDK12 or CCNK, irrespective of DNA damage (Fig. 1A). In contrast, CDK12 knockdown did not affect expression of the HDM2 E3 ligase or the CHK1-related kinase, CHK2. Similar results were obtained in U2OS cells treated with a different genotoxic agent, hydroxyurea (HU) ( Fig. 1B), indicating that the requirement for CDK12 is independent of the type of DNA damage. Of note, CDK12 knockdown also reduced CCNK expression, and vice-versa, indicating that both subunits are required for complex integrity in vivo. Control experiments verified that CHK1 knockdown is sufficient to block p53 induction by DNA damage in U2OS cells (Supplemental Fig. S1B). We conclude that CDK12 acts indirectly, through CHK1, to control p53 stability in response to DNA damage.

We next asked whether CDK12 affects CHK1 mRNA synthesis, as has been observed for other DNA damage response genes (Blazek et al. 2011). Unexpectedly, knockdown of either CDK12 or CCNK had little effect on steady-state CHK1 mRNA levels, regardless of etoposide treatment (Fig. 1C; Supplemental Fig. S1C). Further studies showed that CDK12 had little or no effect on CHK1 protein stability (Fig. 1D; Supplemental Fig. S1D), mRNA accumulation in the cytoplasm, or mRNA $3^{\prime}$ end processing (Supplemental Fig. S1E,F). The effect on CHK1 expression was specific for CDK12 and was not seen in cells depleted of CDK9 or CDK13 (Supplemental Fig. S2A-C). We conclude that CDK12 affects CHK1 kinase expression through an unexpected mechanism that does not involve transcription, mRNA processing, or protein stability.

To examine whether CDK12 affects de novo CHK1 protein biosynthesis, pulse-chase metabolic labeling experiments were carried out in CDK12 knockdown cells. Immunoblot analysis revealed that nascent $\mathrm{CHK} 1$ protein synthesis was strongly reduced in cells deprived of CDK12 (Fig. 1E, top panel), whereas de novo global protein synthesis was unaffected (Fig. 1E, bottom panel). To determine whether CDK12 affects the binding of CHK1 mRNA to 
Choi et al.

A

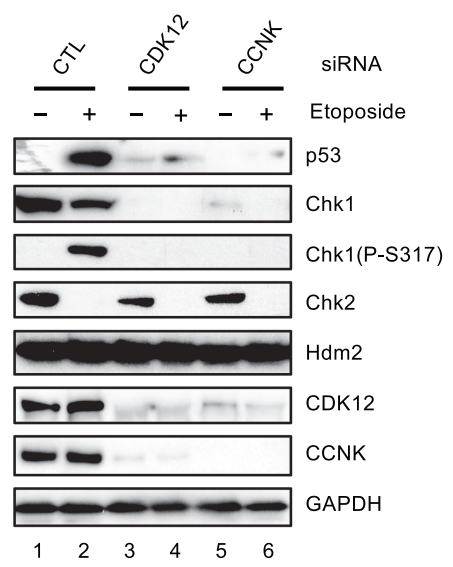

C

E
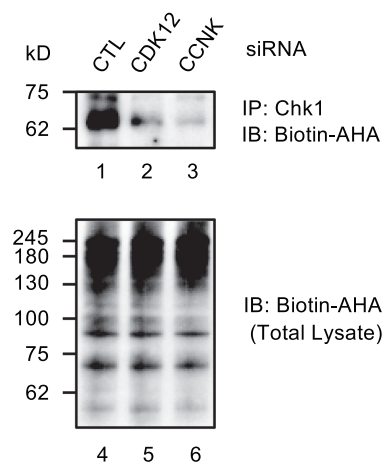

B
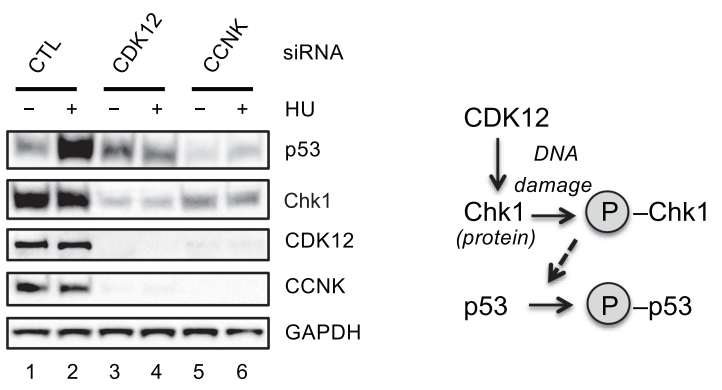

D

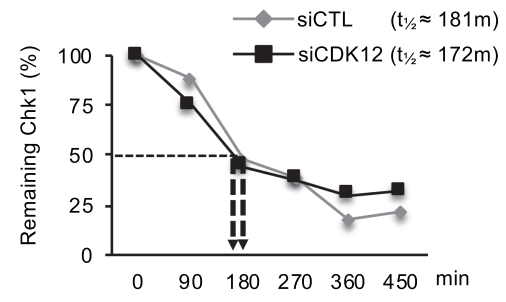

$\mathbf{F}$
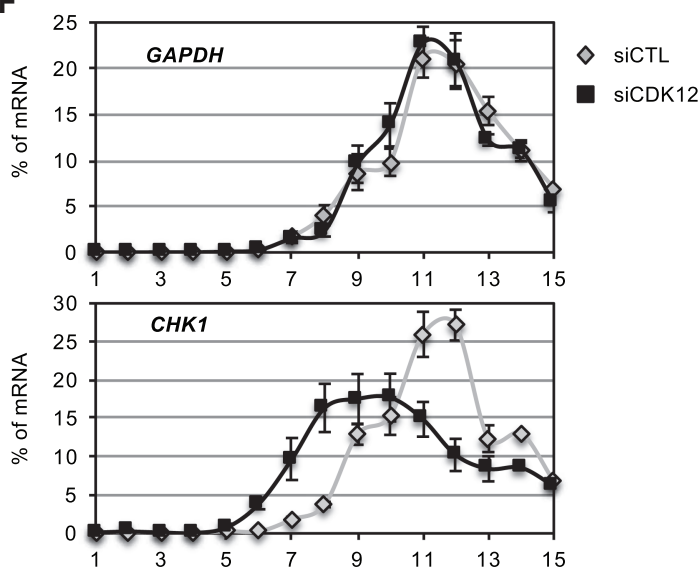

Sucrose $15 \%$

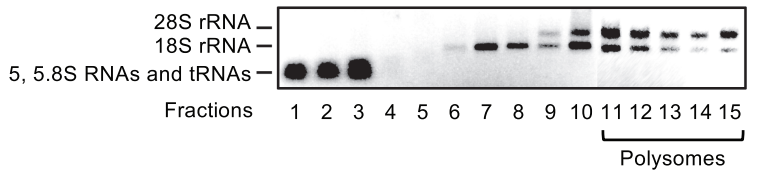

Figure 1. CDK12 selectively regulates CHK1 mRNA translation. (A) Immunoblot analysis of $\mathrm{p} 53$ and CHK1 kinase expression in etoposide-treated U2OS cells. Where indicated, CDK12 or CCNK expression was down-regulated using gene-specific siRNAs, and compared with cells expressing a control (CTL) siRNA. Immunoblot analysis confirmed the siRNA selectivity, and GAPDH was monitored as a loading control. $(B)$ Immunoblot analysis as in $A$, except that DNA damage was induced by HU. The role of CHK1 in the phosphorylation and stabilization of $\mathrm{p} 53$ upon DNA damage is shown in the schematic at the right. (C) Analysis of mRNA levels by quantitative RT-PCR (qRT-PCR) at the indicated genes in cells depleted of CDK12 or CCNK or treated with a control siRNA (siCTL). mRNA levels were normalized to GAPDH mRNA. (D) Measurement of CHK1 protein half-life in cycloheximide (CHX)-treated U2OS cells. The quantification of CHK1 protein levels for this experiment is shown in Supplemental Figure S1D. (E) Analysis of de novo protein synthesis analysis in U2OS cells depleted of CDK12 or CCNK or treated with a control siRNA (CTL). (Lanes 1-3) Cells were pulse-labeled with L-azidohomoalanine (Biotin-AHA), and CHK1 synthesis was monitored by immunoblot of anti-CHK1 immunoprecipitates. (Lanes 4-6) Bulk protein biosynthesis was monitored by immunoblot of total protein input in extracts from control, CDK12-, or CCNK knockdown U2OS cells. (F) Analysis of the polysome distribution of CHK1 and GAPDH mRNAs in control and CDK12 knockdown U2OS cells. The relative distribution of the CHK1 or GAPDH mRNA levels across the sucrose gradient was determined by qRT-PCR of the indicated fractions. For comparison, the sedimentation positions of bulk tRNA and rRNA in denaturing gel are shown at the bottom. 
translating ribosomes, we next analyzed mRNA distribution on polysomes fractionated by sucrose gradients. Importantly, knockdown of CDK12 greatly reduced the amount of CHK1 mRNA cosedimenting with $80 \mathrm{~S}$ and larger polysome fractions (Fig. 1F; Supplemental Fig. S2D). In contrast, the association of GAPDH mRNA with translating polysomes was unaffected in CDK12depleted cells (Fig. 1F, bottom panel), and GAPDH protein levels were similarly unchanged (Fig. 1A,B). Based on these findings, we conclude that CDK12 selectively controls the loading of CHK1 mRNA onto translating ribosomes.

\section{CDK12 phosphorylates $4 E-B P 1$ in vivo and in vitro}

How does CDK12 affect the binding of CHK1 mRNA to polysomes? We next considered the possibility that it might control the binding of translation factors onto the 5' end cap of CHK1 mRNA (Qin et al. 2016). Serum and growth factors activate the $\mathrm{mTORC1}$ kinase, which phosphorylates and releases the 4E-BP1 translation repressor from the 5' cap complex of target mRNAs to stimulate cancer cell growth (Morita et al. 2015). In particular, mTORC1 phosphorylation of 4E-BP1 at T37 and T46 facilitates its release from the mRNA 5' end cap (Fig. 2A; Gingras et al. $1999,2001)$. However, mTORC1 phosphorylation is not sufficient to regulate translation, and additional 4E-BP1 phosphorylation at two Ser-Pro sites (S65 and T70) by an unknown Ser-Pro kinase is also critical (Qin et al. 2016). Consequently, we used 4E-BP1 phosphospecific antibodies to ask whether CDK12 might phosphorylate these specific Ser-Pro sites in vivo. Interestingly, knockdown of either CDK12 or CCNK significantly reduced 4E-BP1
A

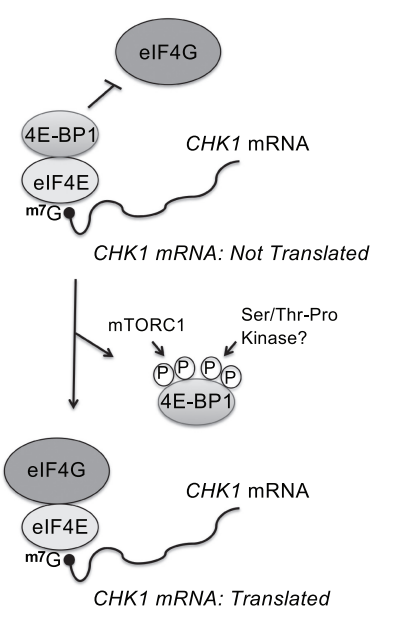

B

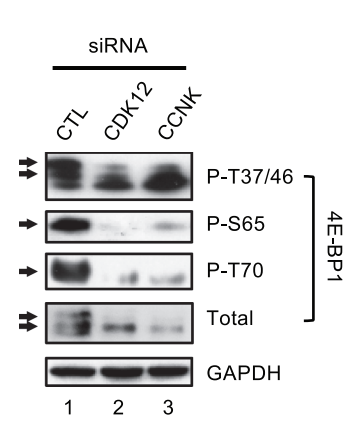

C

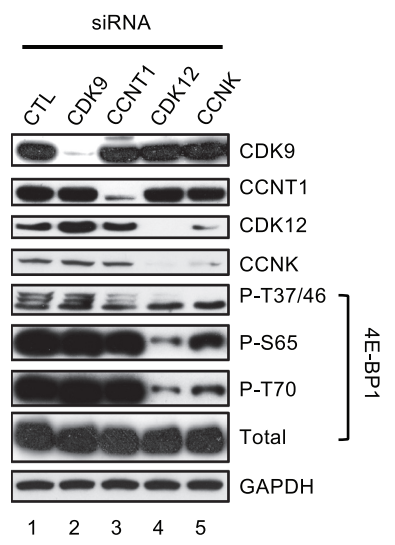

D

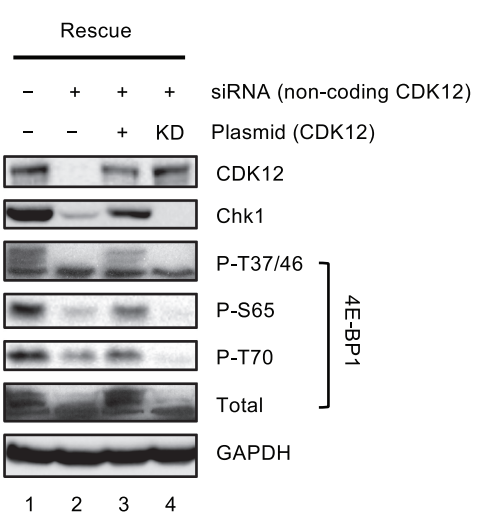

E

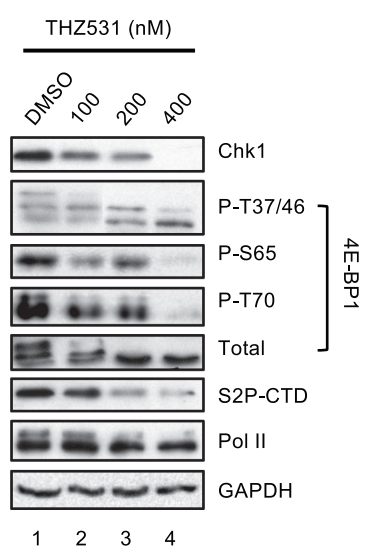

Figure 2. CDK12 phosphorylates 4E-BP1 at S65 and T70 in vivo. (A) Schematic of translation initiation complex assembly at $5^{\prime}$ cap of 4EBP1 target mRNAs. Phosphorylation of 4E-BP1 at T37/T46 by mTORC1 facilitates subsequent phosphorylation at S65 and T70 for release of 4E-BP1 from the cap complex. $(B)$ Immunoblot analysis of 4E-BP1 phosphorylation using phosphospecific antibodies in U2OS cells deprived of CDK12 or CCNK. Arrows indicate hyperphosphorylated forms of 4E-BP1. GAPDH was used as loading control. (C) Immunoblot analysis of 4E-BP1 phosphorylation in U2OS cells depleted of CDK9 or CCNT1 (P-TEFb), or CDK12 and CCNK. (D) Ectopic expression of an RNAi-resistant form of CDK12 rescues CHK1 expression and 4E-BP1 hyperphosphorylation in CDK12 knockdown cells. Following treatment with an siRNA targeting the noncoding region of CDK12, cells were transfected with vectors encoding the wild-type (WT) CDK12 or a CDK12 kinase-dead (KD) mutant (D859A). Native 4E-BP1 phosphorylation was measured by immunoblot as described in $B$. (E) Dose-dependent inhibition of CDK12 by the small molecule kinase inhibitor THZ531 was carried out in U2OS cells, and CHK1 expression and endogenous 4E-BP1 hyperphosphorylation was analyzed by immunoblot as described in $B$. 
phosphorylation at both $\mathrm{S} 65$ and T70, and also decreased bulk 4E-BP1 hyperphosphorylation in vivo, as evident by its changed mobility in the SDS-PAGE (Fig. 2B). In contrast, ablation of CDK12 or CCNK did not affect phosphorylation of 4E-BP1 at the mTORC1-specific sites (T37 and T46). Of note, no changes in the 4E-BP1 phosphorylation or SDS-PAGE migration pattern were observed in cells depleted of the related P-TEFb CTD kinase (CDK9 or CCNT1) (Fig. 2C). As expected, re-expression of wildtype CDK12 in U2OS cells depleted of CDK12 effectively rescued endogenous 4E-BP1 phosphorylation at S65 and $\mathrm{T} 70$, and restored the migration profile of the bulk protein without affecting phosphorylation at T37 or T46 (Fig. 2D). Importantly, neither the phosphorylation nor the migration pattern of endogenous 4E-BP1 was altered in cells expressing a catalytically inactive mutant CDK12 protein (kinase-dead), indicating that the kinase activity of CDK12 is essential for those changes. We conclude that CDK12 controls CHK1 protein expression via phosphorylation and release of 4E-BP1 from target mRNAs, which enables loading of additional translation factors onto the mRNA 5' cap that are needed for association with polysomes and efficient translation.

To validate these results, we addressed whether 4E-BP1 phosphorylation is affected in cells exposed to THZ531, a small molecule kinase inhibitor specific to CDK12 (Mertins et al. 2016). As shown in Figure 2E, THZ531 treatment resulted in a dose-dependent inhibition of 4E-BP1 phosphorylation at S65 and T70 and decreased levels of hyperphosphorylated 4E-BP1 but did not affect phosphorylation at the mTORC1 sites (T37 and T46). Consistent with our results, CDK12 inhibition by THZ531 also reduced CHK1 protein expression and global RNAPII CTD-Ser2 phosphorylation. We conclude that CDK12 can control translation of select target mRNAs by regulating 4E-BP1 phosphorylation at S65 and T70 in vivo.
To determine whether CDK12 cooperates with mTORC1 to phosphorylate 4E-BP1, we next carried out cell-free kinase assays using affinity-purified CDK12 and mTORC1 (Raptor) kinase complexes. As shown in Figure 3A, CDK12 alone weakly phosphorylated recombinant 4E-BP1 at all sites tested in vitro, whereas the mTORC1/Raptor complex readily phosphorylated 4E-BP1 at T37 and T46, but only weakly phosphorylated $\mathrm{S} 65$, and failed to phosphorylate T70. Of note, coincubation of CDK12 with mTORC1 strongly increased 4E-BP1 phosphorylation at S65 and T70 in vitro, without affecting phosphorylation at T37 or T46 (Fig. 3A). The ability of CDK12 to cooperate with mTORC1 strongly supports the two-step mechanism of 4E-BP1 phosphorylation originally proposed by Gingras et al. (1999, 2001). To validate the mechanism, we purified and analyzed a series of 4E-BP1 point mutant proteins in reconstituted kinase reactions containing both CDK12 and mTORC1/ Raptor complexes. As shown in Figure 3B, immunoblot analysis with phosphospecific antisera revealed that alanine substitution at either T37 or T46 was sufficient to block 4E-BP1 phosphorylation at the mutated site and also effectively reduced phosphorylation at S65 and T70 (lanes 2,3), suggesting that phosphorylation by mTORC1 primes 4E-BP1 for subsequent phosphorylation by CDK12. In contrast, mutation of S65 or T70 had no effect on phosphorylation at T37 and T46, suggesting that mTORC1 acts independently of CDK12. Finally, the catalytically inactive (kinase-dead) CDK12 failed to phosphorylate 4E-BP1 in vitro, either alone or in combination with mTORC1 (Fig. 3C), ruling out any kinase-independent activity of CDK12 on S65 and T70 phosphorylation. In summary, these data strongly suggest that CDK12 cooperates with mTORC1 to phosphorylate and release 4E-BP1 from target mRNAs (Fig. 3D).

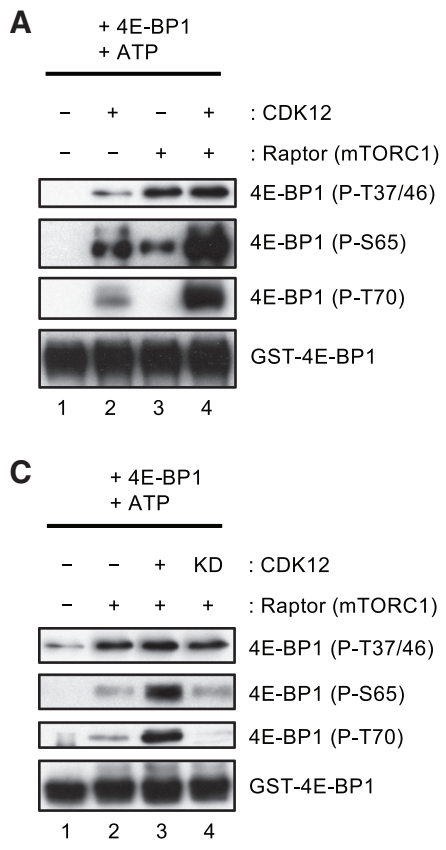

B
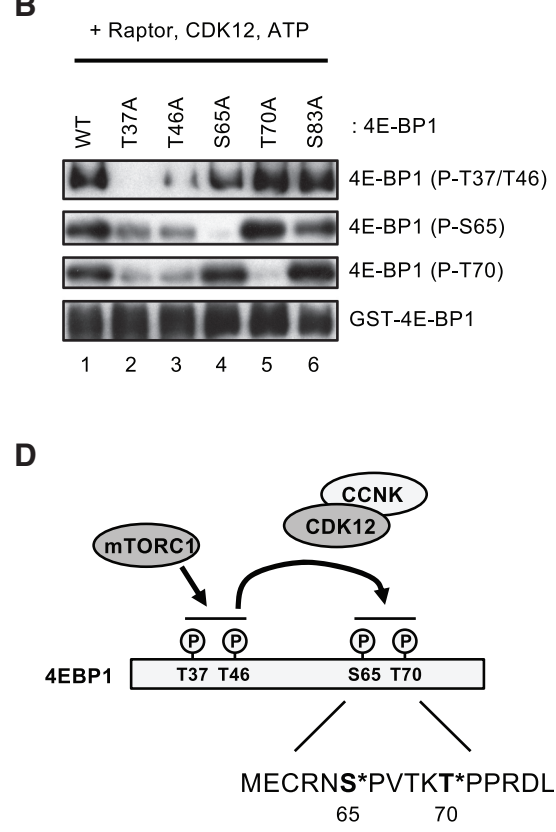

Figure 3. mTORC1 phosphorylation primes 4E-BP1 for CDK12 phosphorylation in vitro. (A) In vitro kinase assay using affinity-purified Raptor (mTORC1) and CDK12 kinase complexes. Cell-free kinase assays were reconstituted with purified recombinant 4E-BP1 protein and ATP, as indicated. Immunoblot analysis was carried out as in Figure 2B. (B) Cell-free kinase assays with recombinant wild-type and phosphorylation site point mutant 4E-BP1 proteins. Reactions contained affinity purified CDK12 and Raptor (mTORC1) kinases, as described in $A$. (C) Analysis of 4E-BP1 phosphorylation in reactions containing affinity-purified wild-type (WT) or kinase-dead (KD) form CDK12 complexes, as described in $A$. (D) A schematic of the two-step phosphorylation model for 4E-BP1, where mTORC1 facilitates subsequent CDK12 phosphorylation at two consensus Ser-Pro sites (S65 and T70). 
RNA immunoprecipitation coupled with deep sequencing (RIP-seq) identification of $m R N A$ s that bind eIF4G in a CDK12-dependent manner

To address whether CDK12 controls the binding of translation initiation factors to target mRNAs, RIP experiments were carried out using antisera specific to eIF4E and eIF4G in extracts from CDK12 knockdown cells. As shown in Figure 4A, lowered levels of CDK12 did not affect binding of eIF4E to CHK1 mRNA, indicating that the capping of CHK1 mRNA was unaffected. In contrast, CDK12 depletion significantly reduced CHK1 mRNA binding to eIF4G. Of note, translation factor binding to GAPDH mRNA was unaffected by CDK12 knockdown, as expected, and CDK12 had no effect on expression of eIF4E or eIF4G (Supplemental Fig. S3A). We conclude that the inability of $C H K 1$ mRNA to associate with eIF4G is due to a failure to phosphorylate and release 4E-BP1 from the cap structure, and this underlies its failure to associate with translating polysomes in CDK12-deficient cells.

To identify other mRNAs that rely on CDK12 for binding to eIF4G, we carried out a RIP-seq analysis of eIF4Gimmunoprecipitates in extracts from U2OS cells. For comparison, a RIP-seq analysis was also carried out in extracts from cells treated with the mTORC1 inhibitor Rapamycin. To identify genes that depend on CDK12 for mRNA biosynthesis we also carried out RNA-seq experiments, and genes that showed a difference in steady-state mRNA levels in CDK12 knockdown or rapamycin-treated cells ( $\log _{2}$ fold change $>1 ; 561$ and 640 genes, respectively) (Supplemental Fig. S3B) were excluded from further consideration. Above this threshold, 2780 Rapamycin-sensitive mRNAs were identified that bind efficiently to eIF4G $\left(\log _{2}\right.$ fold change $\left.>0.5\right)$ in a manner that depends on the mTORC1 kinase. This experiment also identified 1033 "translation-only" mRNAs that depend on CDK12 to associate with eIF4G $\left(\log _{2}\right.$ fold change $\left.>0.4\right)$. As shown in the Venn diagram in Figure 4B, 39\% (391 among 1033) of the CDK12-dependent mRNAs were also sensitive to Rapamycin. Further analysis of these genes (Fig. 4C; Supplemental Fig. S3C) revealed that 32 of the top 50 CDK12-dependent mRNAs were among the top 100 Rapamycin-sensitive genes, and, vice versa, 29 of the top 50 Rapamycin-sensitive genes were among the top 100 CDK12-dependent mRNAs (Fig. 4D). Consequently, most of the highly ranked mRNAs in each group require both CDK12 and mTORC1. Consistent with this finding, gene ontology (GO) analysis of the RIP-seq results revealed that many of the CDK12-dependent mRNAs encode factors required for ribosome biogenesis, translation, and mRNA processing (Fig. 4E; Supplemental Fig. S3D,E). Most importantly, these data show that a large number of mRNAs are jointly regulated by CDK12 and mTORC1 (Rapamycin-sensitive).

We also noted that some of the mRNAs identified in the RIP-seq database were regulated by CDK12 or mTORC1 (Rapamycin) but not both kinases. To verify the RIP-seq data, a subset of genes representative of each of the three categories (Supplemental Fig. S3F) was analyzed by RIP for binding to eIF4G in cells treated with control or
CDK12-siRNAs. As shown in Figure 4F, the tested genes confirmed that different subsets of mRNAs depend on CDK12, mTORC1 (Rapamycin), or both kinases for efficient binding to eIF4G. Because Rapamycin does not uniformly block all 4E-BP1 phosphorylation (Kang et al. 2013), these data may underestimate the number of bona fide $\mathrm{mTORC1}$ substrates that also require CDK12. Alternatively, CDK12 or mTORC1 may cooperate with distinct 4E-BP1 kinases to regulate access of eIF4G to some mRNAs. We conclude that CDK12 regulates binding of eIF4G to a specific subset of mRNAs, including many mTORC1 targets.

Activation of oncogenic pathways often leads to hyperphosphorylation and inactivation of 4E-BP1 (Biffo et al. 2018). Independent of its role in transcription, MYC can drive oncogenic transformation by regulating ribosome biogenesis, translation, and creation of the mRNA 5' end cap (van Riggelen et al. 2010). Because inactivation of 4EBP1 is crucial for MYC transformation (Pourdehnad et al. 2013), it was important to assess whether CDK12 is also required for this process. However, CDK12 inhibition by knockdown or chemicals significantly reduced cell viability in long-term culture (4 d or longer). Consequently, we sought to identify a dominant-negative inhibitor of CDK12 that could be used instead to assess its role in MYC transformation. As shown in Supplemental Figure S4A, we determined that an N-terminal fragment of CDK12 (amino acids 1-787), lacking the kinase domain, was sufficient to bind CCNK in vivo, and reasoned that overexpression of this fragment should inactivate CDK12 kinase activity by sequestering CCNK into inactive complexes. As anticipated, ectopic expression of the CDK12 (amino acids 1-787) dominant-negative mutant significantly reduced p53 induction in etoposide-treated U2OS cells (Supplemental Fig. S4B). Moreover, the CDK12 mutant was not cytotoxic to cell growth over the time frame of this experiment. In contrast, expression of either fulllength CDK12 or a large CTD fragment (amino acids 148-1490) that spans the kinase and CCNK-binding domains, enhanced p53 induction by etoposide. We conclude that CDK12 is a limiting factor for the p53 response to DNA damage.

To assess whether the dominant-negative CDK12 protein affects MYC transformation, Ratl a cell lines that stably express MYC were isolated and used to examine the role of CDK12 in anchorage-independent cell growth. As shown in Figure 5A, Ratla cells expressing either the vector control or CDK12 (amino acids 1-787) alone were unable to proliferate in the solid matrix, whereas cells that express MYC readily formed colonies over a 15-d span of the experiment, as expected. Notably, stable coexpression of the CDK12 (amino acids 1-787) mutant in MYC-expressing Ratla cells significantly reduced the number of colonies formed in soft agar (Fig. 5B). Of interest, expression of wild-type CDK12 did not change the total colony number (>50 $\mu \mathrm{m}$ diameter; Fig. $5 \mathrm{~B}$ ), but greatly increased the number of large colonies formed (>200 $\mu$ m diameter; Fig. $5 \mathrm{C}$ ), indicating that CDK12 stimulates the rate of anchorage-independent growth initiated by MYC. To assess whether the CDK12 cooperates with MYC to enhance 
Choi et al.

A
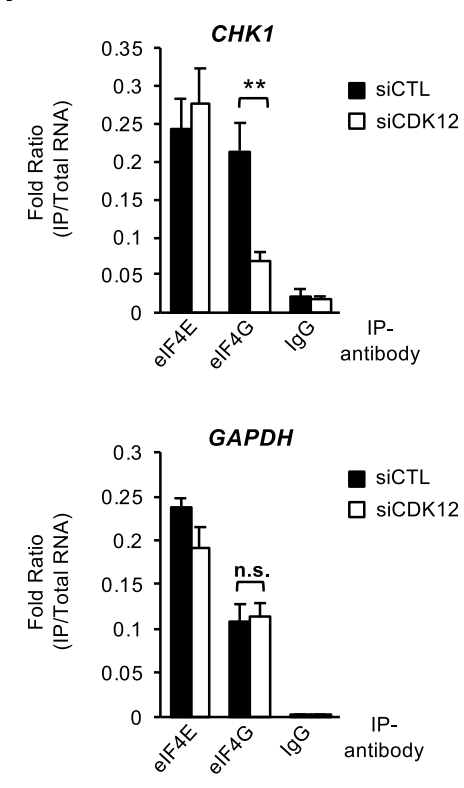

B

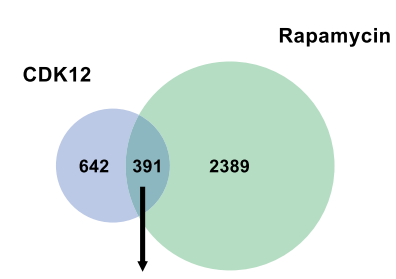

CDK12-Dependent \& Rapamycin-Sensitive Genes
E

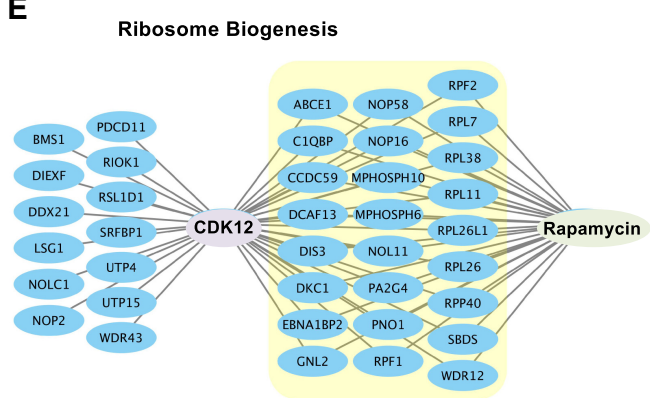

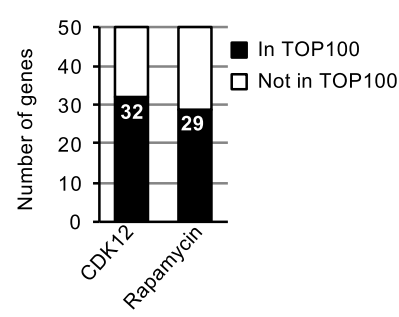

C

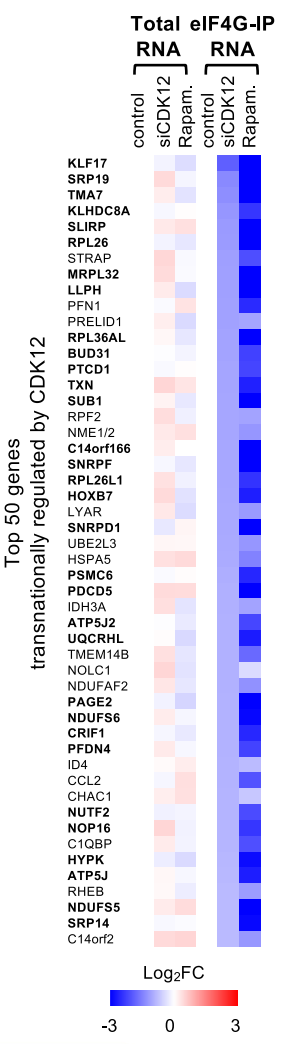

$\mathbf{F}$

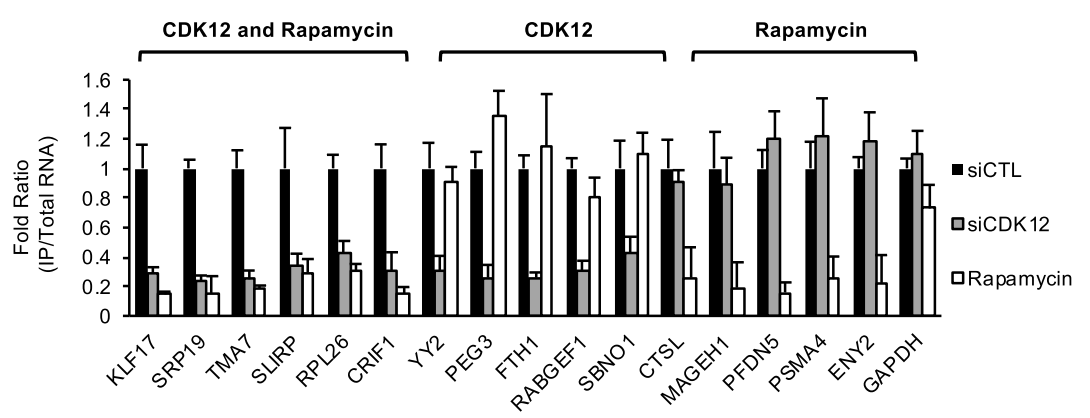

Figure 4. CDK12 regulates binding of eIF4G to a subset of mTORC1-dependent mRNAs. (A) RIP analysis of U2OS cells depleted of CDK12. Protein complexes were immunoprecipitated from siRNA-treated cells using indicated antibodies, and mRNAs were assessed by qRT-PCR and normalized to input. Asterisks indicate statistically significant changes $\left(^{*}\right) P<0.05$; $\left.{ }^{* *}\right) P<0.01$; (n.s) nonsignificant differences $(P>0.05)$. All values represent the mean + SD from $n=3$. The results are representative of three independent experiments. (B) Venn diagram summarizing the number of mRNAs that depend on CDK12, mTORC1 (Rapamycin-sensitive), or both to bind eIF4G in U2OS cells, as determined by RIP-seq analysis. (C) Identification of the top 50 mRNA species that associate with eIF4G in a CDK12-dependent or Rapamycin-sensitive manner, as identified by RIP-seq analysis from $B$. For comparison, changes in total mRNA abundance are also shown in $\log _{2}$ scale. $(D)$ Summary of the extent to which the top 100 CDK12-dependent mRNAs are also sensitive to Rapamycin (mTORC1-dependent) for binding to eIF4G, and vice versa. (E) Linkage analysis of top CDK12-dependent genes identified by RIP-seq (in B). A complete gene ontology (GO) analysis of CDK12-regulated mRNAs is shown in Supplemental Figure S3D. The mRNAs in the yellow box are coregulated by CDK12 and mTORC1 (Rapamycin-sensitive). (F) Validation of the RIP-seq results for a subset of mRNAs. Binding of eIF4G to selected mRNAs was assessed by RIP experiments for dependence on CDK12 or mTORC1, or both, as indicated, based on the top genes in each category shown in Supplemental Figure S3F. 
A
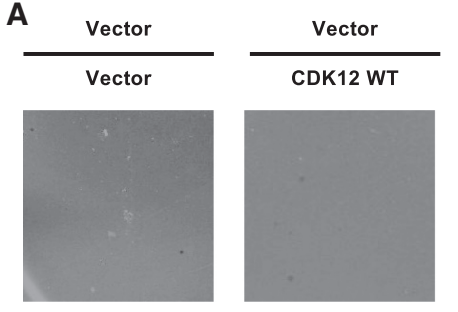

B

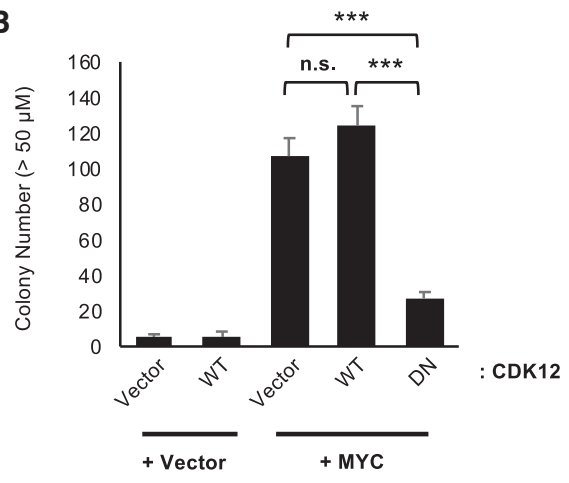

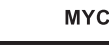

CDK12 WT

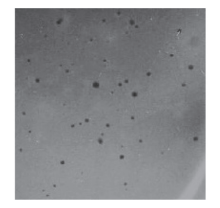

C

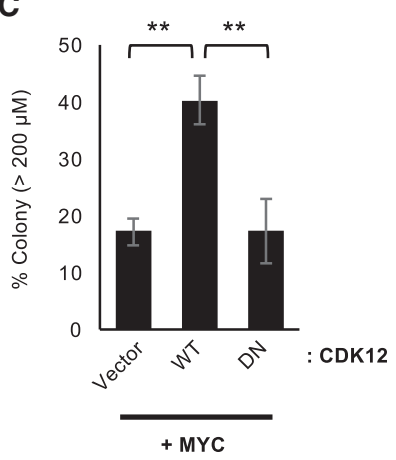

D
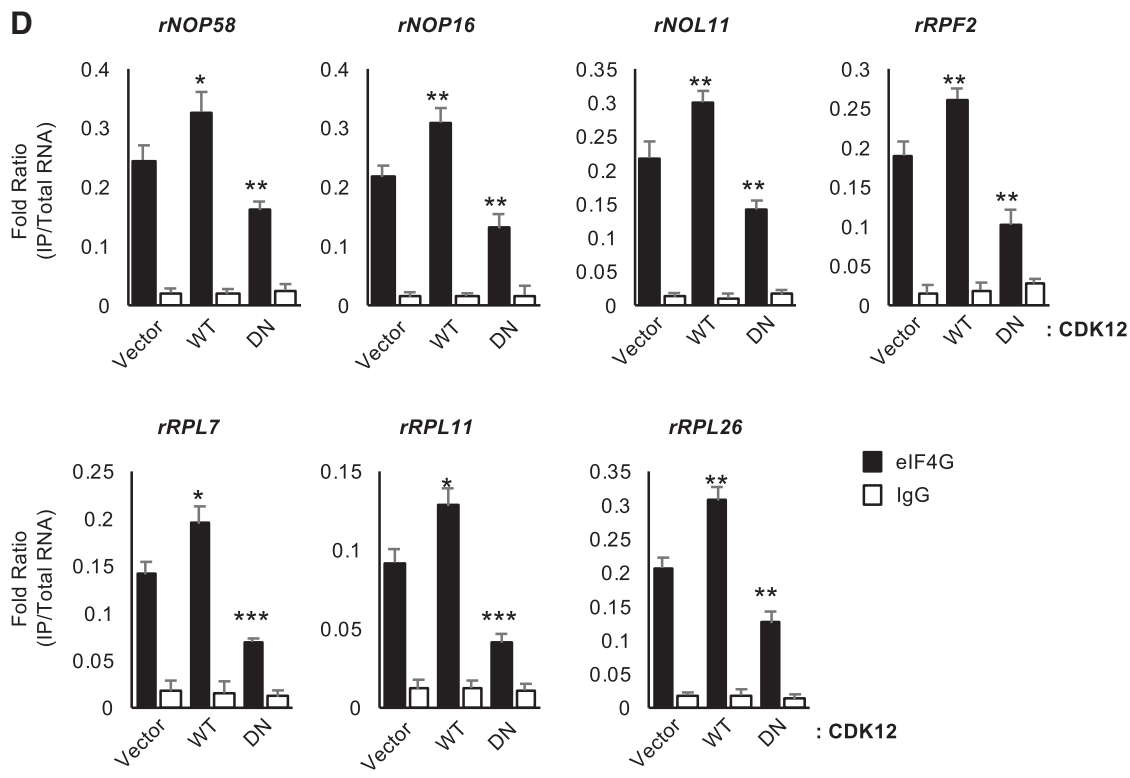

Figure 5. CDK12 regulates $\mathrm{mTORC} 1$ targets critical for MYC transformation. (A) Analysis of anchorage-independent growth on soft agar in Ratla cells expressing MYC, alone or in combination with wildtype (WT) or dominant-negative (DN) CDK12. (B) Effect of wild-type or dominant-negative CDK12 on the total number of measurable colonies ( $>50 \mu \mathrm{m}$ ) formed in soft agar, as shown in $A$. (C) Bar graph quantification of the percentage of large colonies $(>200 \mu \mathrm{m})$ formed in cells expressing a control vector and either wild-type (WT) or dominant-negative (DN) CDK12. (D) RIP analysis of the requirement of CDK12 for eIF4G binding to specific mRNAs required for MYC transformation in Ratla-MYC cells that express vector, wild-type (WT), or dominant-negative (DN) CDK12 as described in C. Asterisks indicate statistically significant changes as determined by $t$-test (*) $P<0.05$; (**) $P<0.01$; (**) $P<0.001$; (n.s) nonsignificant change. All values represent the mean + SD from three independent experiments $(n=3)$. translation, RIP analysis was carried out to examine binding of eIF4G to known mTORC1-dependent mRNAs required for transformation. As predicted, expression of the dominant-negative CDK12 (amino acids 1-787) mutant strongly decreased binding of eIF4G to these mRNAs (Fig. 5D). Taken together, these data indicate that CDK12 can facilitate MYC transformation by promoting the translation of mTORC1 target mRNAs, many of which encode oncogenic factors.

\section{Ribosome profiling identifies specific mRNAs that are translated in a CDK12-dependent manner}

To define the role of CDK12 in selecting mRNAs for active translation, we used ribosome profiling (Ingolia
2016) to measure mRNA translation efficiency genomewide. RNA deep-sequencing (Ribo-seq) analysis of ribosome-protected mRNA fragments (RPFs), derived from control or CDK12 knockdown U2OS cells, was used to survey the differential ribosome occupancy of individual mRNA species. Metagene analysis revealed that a high fraction $(>75 \%)$ of reads occurred in-frame with the coding regions of the annotated genes (Supplemental Fig. S5A), demonstrating the high resolution of the Ribo-seq data. In parallel, mRNA levels in each sample were quantified by high-throughput RNA sequencing (RNA-seq) to control for the change in RPF abundance due to altered copy number derived from mRNA biosynthesis. Through this approach, it was possible to differentiate between CDK12 transcription and translation candidates. After 
establishing probability distributions for $\log _{2}$ fold changes of mRNA and RPF using the Xtail method (Xiao et al. 2016), we accurately assessed the differential translation efficiency created by genome-wide depletion of CDK12 (Fig. 6A). The Xtail analysis also provided the statistical significance of differential translation for each gene, as shown in the volcano plot listing of fold changes (Supplemental Fig. S5B).

To define the most extreme set of translation-controlled mRNAs, we excluded transcripts with weak changes (i.e., both transcriptional and translational differences of less than twofold), or with low statistical significance (adjusted $P$-value $>0.1)$. This approach yielded a list of 410 genes for which the translation efficiency was severely affected upon depletion of CDK12 (Supplemental Figs. S5C, S6A). We further ruled out potential transcriptional effects by eliminating genes that were categorized as "transcription-only" or "homodirectional" as well as genes with up-regulated translation efficiency in CDK12 knockdown cells. This refinement resulted in a list of 172 "translation-only" target genes (Supplemental Table S3), which showed an impaired translation efficiency in cells deprived of CDK12 (Fig. 6B). Consistent with our earlier findings, CHK1 was included among the list of genes that depend on CDK12 for translation.

Read coverage plots of the Ribo-seq and RNA-seq data for several of the 172 translationally down-regulated genes showed a dramatic decrease in ribosome occupancy without significant changes to mRNA levels in CDK12depleted cells (Fig. 6C; Supplemental Fig. S6A). Under these conditions, differential RNA-seq analysis identified 1516 genes that were regulated by CDK12 at the level of mRNA abundance and not translation efficiency, and these were not evaluated further. To examine how CDK12 controls the translation of the set of targets identified by Ribo-seq, several candidate mRNAs were analyzed in greater detail (Supplemental Fig. S5D). First, we confirmed that CDK12 had no effect on the steady-state mRNA levels of the these putative "translation-only" target genes (Fig. 6D, top panel). Consistent with the genomewide Ribo-seq data, RIP analysis confirmed strongly reduced binding to eIF4G to these target mRNAs in CDK12 knockdown cells (Fig. 6D, bottom panel). Immunoblot analysis was used to validate that CDK12 regulates the protein expression of each of the tested genes (Fig. 6E). We conclude that CDK12 facilitates translation of the tested mRNAs through the same mechanism used to regulate CHK1 expression; namely, by promoting the phosphorylation of 4E-BP1 to enable loading of the eIF4G translation initiation complex onto the mRNA 5' cap.

\section{CDK12 translation targets include many chromosome and centromere family proteins}

The Ribo-seq data set identified 126 up-regulated and 172 down-regulated "translation-only" target genes in U2OS cells (Supplemental Fig. S6A). GO enrichment analyses revealed that many of the down-regulated genes from the "translation-only" group are involved in mRNA processing, as was also observed in the RIP-seq analysis (Supple- mental Fig. S6B). Most interestingly, the most prominent CDK12-dependent translation target genes included many families of proteins that reside in complexes critical for centromere-kinetochore architecture, mitotic spindle regulation, and chromosome segregation. These CDK12 translation targets include a majority of subunits of the CENP, CEP, and SMC complexes as well as NDC80, NUF2, MIS12, and other well-established mitotic regulators (Supplemental Fig. S6C). To validate these results, we confirmed strongly reduced protein levels for several of these mitotic regulators in CDK12 and CCNK knockdown cells (Supplemental Fig. S6D).

To further investigate whether CDK12 is important for mitotic progression, we carried out a series of confocal imaging experiments in cells deprived of CDK12 or CCNK. As shown in Figure 7A, severe chromosome misalignments were readily apparent in CDK12-depleted metaphase cells, many of which constituted defective spindle-kinetochore attachments (Zhang et al. 2018). To determine the degree of chromosome misalignment, metaphase chromosomes were quantitatively assessed by immunostaining for CENP-B foci at centromeres (Fig. 7B; Supplemental Fig. S7A). Importantly, this approach revealed significant misalignments involving multiple chromosomes within a given cell. Because misaligned chromosomes at metaphase directly activate the spindle SAC, which ensures that chromosome kinetochores are properly attached to the mitotic spindle for segregation prior to the onset of anaphase (Musacchio 2015), we also evaluated whether CDK12 knockdown activates the SAC. A key step in the active SAC is the recruitment of BubR1, an essential component of the mitotic checkpoint complex (MCC) (Kapanidou et al. 2015), to the unattached kinetochores. BubR1 is prominently localized to chromosomes in prometaphase, when the majority of chromosomes are not aligned to the metaphase plate. As shown in Figure 7C (top and middle panels), BubR1 levels were dramatically reduced at metaphase in cells treated with a control siRNA, as expected, whereas BubR1 was retained on misaligned chromosomes at each spindle pole side during metaphase in the CDK12-depleted cells. These data strongly suggest an unsatisfied status of the SAC and a significantly impaired transition to anaphase in CDK12deprived cells. To assess whether the activated SAC delayed mitosis by preventing the onset of anaphase, we quantified the mitotic cell population in these cells. Tilescanning image analysis revealed a doubling ( $8 \%)$ of the number of total mitotic cells in CDK12 knockdown cells, as compared with cells expressing a control siRNA (Fig. 7D, left panel; Supplemental Fig. S7B). Further inspection of the mitotic subpopulation revealed a dramatic increase in metaphase-arrested cell population among cells exposed to the CDK12 siRNA(Fig. 7D, right panel). Taken together, these data indicate that CDK12-deficient cells are severely impaired for mitotic progression due to activation of the SAC. Moreover, chromosome misalignments were frequently accompanied by asymmetric spindles or spindle pole detachment during mitosis (Tame et al. 2016). Importantly, these spindle pole defects were also observed in CCNK-deficient cells and frequently resulted in a severe 
A

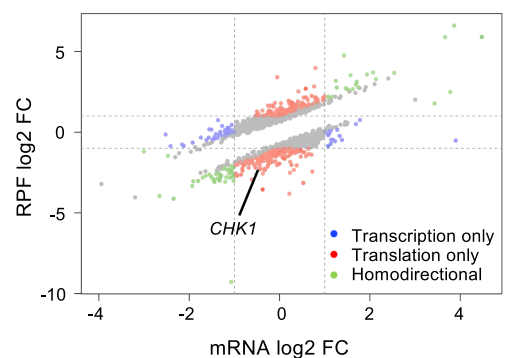

C
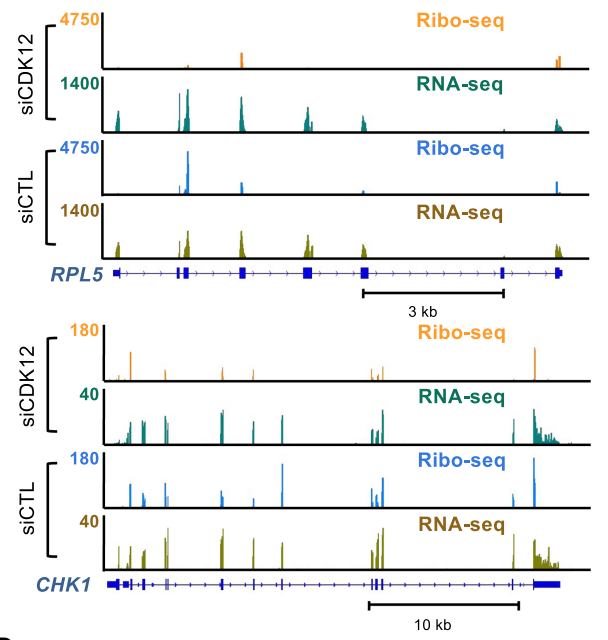

D
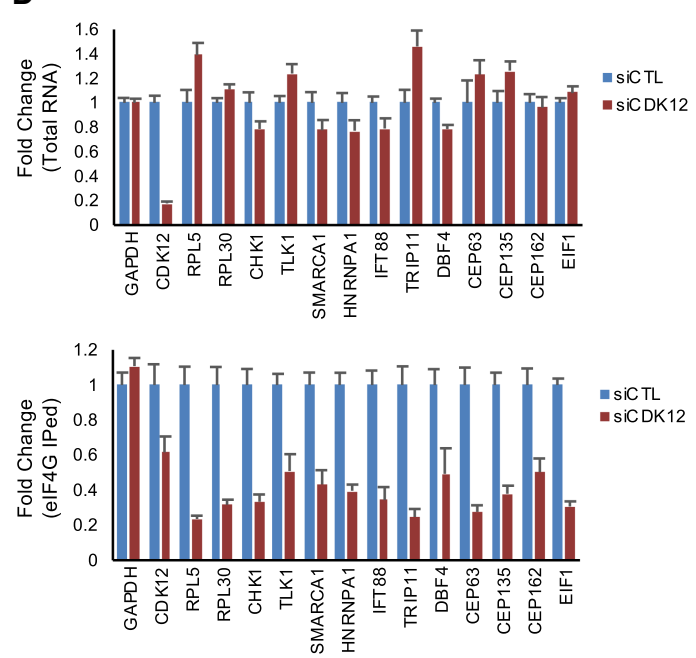

B
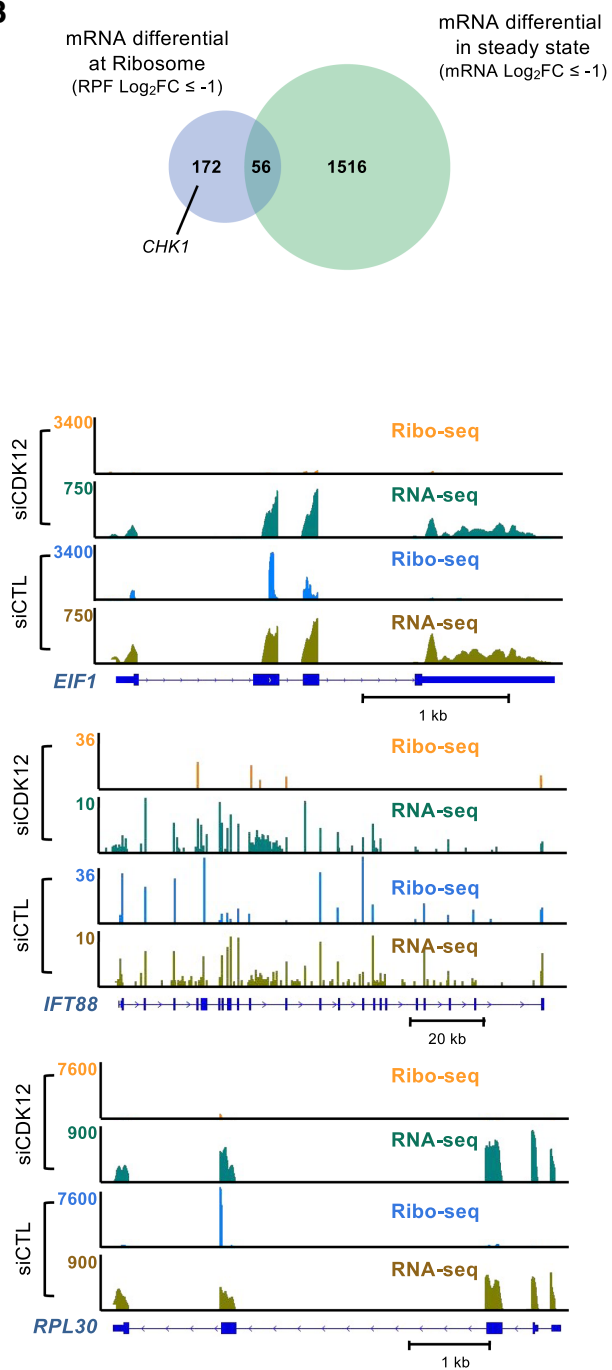

$E$

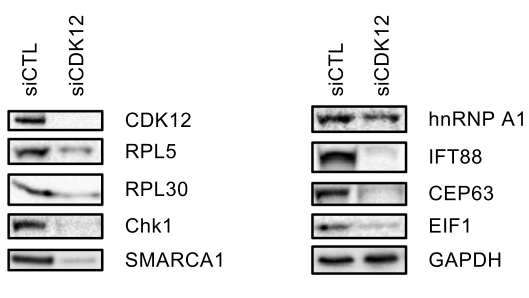

Figure 6. Genome-wide ribosome profiling identifies CDK12-dependent translation target genes, including mRNAs encoding critical centromere and kinetochore complexes. (A) Scatter plot representation of the genome-wide fold-changes of RPFs and mRNA abundance in U2OS cells depleted of CDK12. The differential translation efficiency $\left(\log _{2}\right.$ fold change $\geq 1$ and $\leq-1$; false discovery rate [FDR] $\left.\leq 0.1\right)$ was plotted for mRNAs subject to transcriptional regulation ("transcription-only"; blue points), translational regulation ("translation-only"; red points), and homodirectional changes in both processes ("homodirectional; green points). The CHK1 gene was identified in the downregulated group of "translation-only" CDK12 targets. (B) Venn diagram displays the number of genes down-regulated at the level of transcription (green), translation (blue), or both (overlapping) from $A$. Note that CHK1 was present in the group of "translation-only" target genes. (C) BedGraphs of total mRNA levels (RNA-seq) and RPFs (Ribo-seq) for the RPL5, CHEK1, EIF1, IFT88, and RPL30 genes in U2OS cells treated with control (CTL) or CDK12-specific siRNAs. The five genes shown fall in the category of "translation-only" targets of CDK12. Scales represent the genomic DNA size and structure of the coding region of the individual genes. (D) RIP analysis of selected candidate "translation-only" CDK12 target mRNAs that were identified by Ribo-seq. The top panel shows total steady-state mRNA levels in cells transfected with control (CTL) or CDK12-siRNAs by qRT-PCR, and the bottom panel displays the mRNAs bound to eIF4G in each condition, as determined by RIP. All values represent the mean \pm SD from three independent experiments $(n=3)$. $(E)$ Immunoblot analysis of protein expression for select CDK12 "translation-only" target genes. Several genes from $D$ were tested by immunoblot to monitor protein expression using the indicated antisera. 
Choi et al.
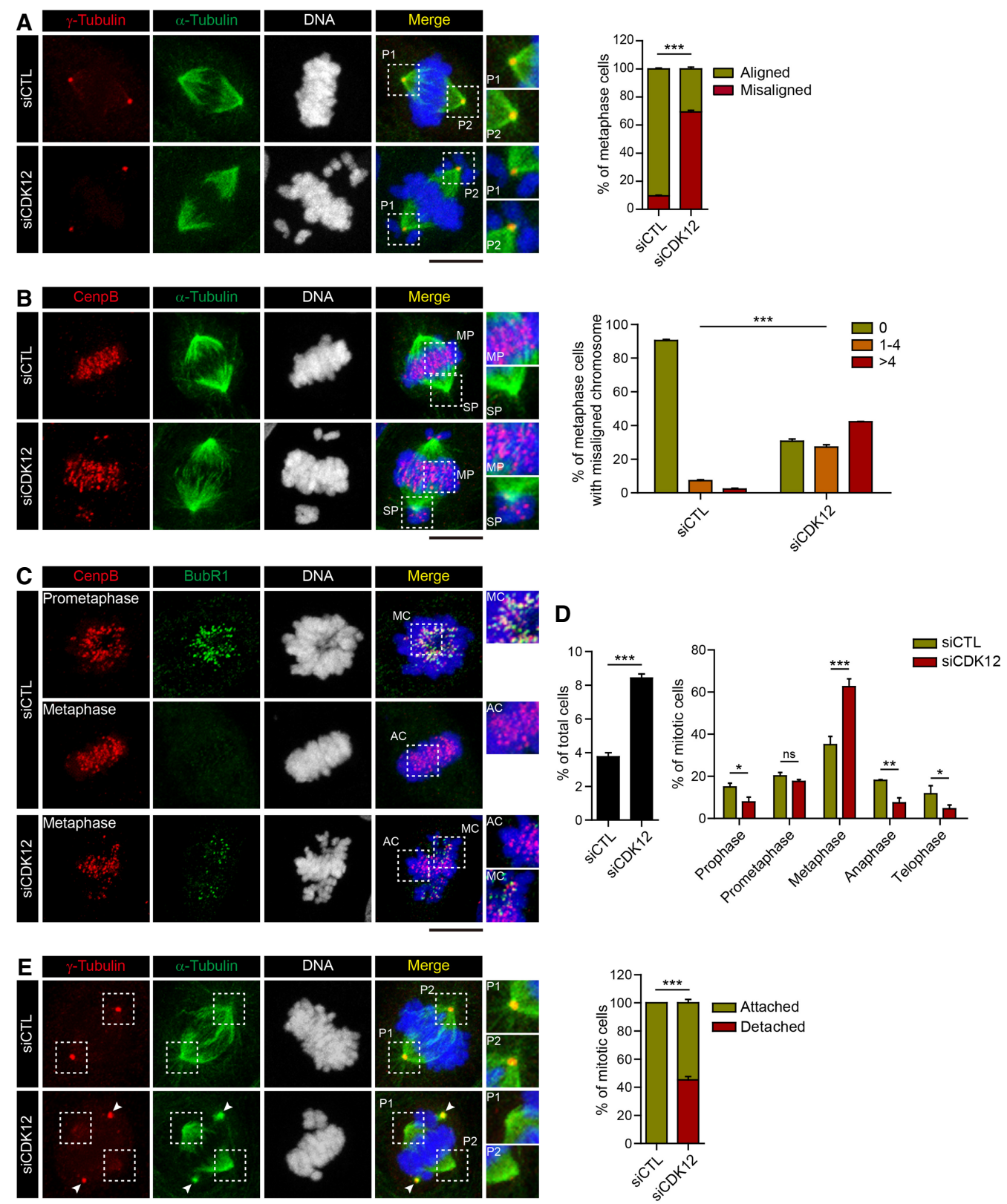

Figure 7. CDK12 is critical for proper chromosome alignment and progression through mitosis. (A) Confocal imaging reveals chromosome misalignments during metaphase in U2OS cells depleted of CDK12. Cells were immunostained for $\gamma$-Tubulin (red), $a$-Tubulin (green), and DNA (DAPI; gray) after transfection with control (CTL) or CDK12-specific siRNAs. The magnified insets show chromosome misalignments at each spindle pole (P1 and P2). The graph at the right displays the number of metaphase cells containing misaligned chromosomes from experiments done in triplicate (>100 cells each) for control or CDK12 knockdown cells. $(B)$ Quantification of misaligned chromosomes in CDK12-depleted cells. Confocal image analysis was carried out as in $A$ with immunostaining for CENP-B (red), $\alpha$-Tubulin (green), and DNA (DAPI; gray). Magnified insets show CENP-B foci at the metaphase plate (MP) or the spindle pole (SP). The number of misaligned chromosomes at the spindle poles was scored by counting CENP-B foci. The results were divided into three groups, based on the number of misaligned chromosomes per cell $(0,1-4$, and $>4)$, and the results were graphed from experiments carried out in triplicate (>100 cells each). (C) Analysis of SAC activity (BubR1 level at chromosomes) in metaphase cells. BubR1 (green) was detected by immunostaining and confocal microscopy, as described in $A$. The magnified insets highlight misaligned chromosomes (MC) and aligned chromosomes (AC), respectively. (D) Inhibition of mitotic progression in cells depleted of CDK12. The bar graph at the left plots the percentiles of mitotic cells from total cell populations treated with the indicated siRNAs shown in tile scan analysis (Supplemental Fig. S7C). The graph at the right quantifies the subpopulations in mitotic cells in cells treated with control (CTL) or CDK12-specific siRNAs. (E) Frequent spindle pole detachments are observed in CDK12-deficient cells. Confocal imaging was analyzed as described in $A$. The bar graph shows the percentile of cells containing abnormal spindle pole detachments, as quantified from total mitotic populations analyzed in triplicate $\left(>100\right.$ cells each). For $A-E$, asterisks indicate the statistically significant changes determined by unpaired $t$-test. $\left({ }^{*}\right) P<0.1 ;\left({ }^{* *}\right) P<0.01 ;\left({ }^{* * *}\right)$ $P<0.001$. Bars, $10 \mu \mathrm{m}$. Error bars indicate + SD. 
disorientation of the mitotic division axis (Fig. 7E; Supplemental Fig. S7B). Taken together, these results uncover a new set of target genes regulated by CDK12:CCNK, which leads to the concerted translation of mRNAs encoding factors that govern chromosome alignment and mitotic fidelity.

\section{Discussion}

Here we report that, in addition to its role in mRNA biosynthesis for DNA repair genes, CDK12 plays a unique role in the regulated translation of a specific subset of mRNAs. The observation that CDK12 regulates $\mathrm{CHK} 1$ protein expression at the level of translation, led to the discovery that CDK12 directly phosphorylates the 4E-BP1 translation repressor at $\mathrm{S} 65$ and $\mathrm{T} 70$ in vivo and in vitro and controls the exchange of 4E-BP1 with eIF4G at $C H K 1$ and other target mRNAs. Our data strongly indicate that CDK12 cooperates with mTORC1 to phosphorylate 4E-BP1 and support an earlier model in which phosphorylation by mTORC1 was proposed to prime 4E-BP1 for subsequent phosphorylation by an unknown Ser-Pro kinase (Gingras et al. 1999, 2001). Using RIP-seq analysis, we show that CDK12 controls binding of eIF4G to 1000 mRNAs, many of which are known targets of $\mathrm{mTORC1}$ and are sensitive to Rapamycin. The genome-wide ribosome profiling data further revealed a critical role for CDK12 in the translation of mRNAs encoding CENP, CEP, and SMC subunits as well as other key subunits of centrosome, centromere, and kinetochore complexes. Confocal imaging studies revealed CDK12 depletion causes severe mitotic defects, including chromosome misalignments, spindle pole detachment that leads to activation of the SAC. Loss of these functions likely contributes to the distinctive genotype and aggressive properties of metastatic cancers that harbor CDK12-inactivating mutations.

The discovery that CDK12 has a role in translation is interesting in light of earlier reports that the Saccharomyces cerevisiae ortholog of CDK12, the Ctk1/CTDK-I CTD kinase complex (Bartkowiak et al. 2010; Bowman and Kelly 2014) stimulates mRNA translation globally (Röther and Sträßer 2007; Coordes et al. 2015). Unlike CDK12, however, the yeast CTDK-I stimulates mRNA translation globally, affecting both general initiation and elongation steps in the process. In contrast, we found that CDK12 controls only a specific subset of mRNAs that are sensitive to CDK12-dependent phosphorylation and inactivation of the 4E-BP1 translation repressor. These mRNAs include TOP motif-containing targets of $\mathrm{mTORC} 1$ as well as genes involved in cell proliferation, DNA repair, mitochondria function, and mitosis. These distinct actions of CDK12 and Ctk1 may reflect the absence of a 4E-BP1 homolog in yeast, and the greater diversity and regulation of mRNA cap complex assemblies in metazoans.

Given that CDK12 is an RNAPII-associated kinase predominantly localized in the nucleus, how does it cooperate with mTORC1 to regulate translation? Many mTORC1 subunits, including Raptor, are partly localized to the nucleus, as are 4E-BP1 and eIF4E, the latter of which can con- trol the nuclear export of specific mRNAs (Osborne and Borden 2015; Borden 2016). Consequently, CDK12 may phosphorylate 4E-BP1 in the nucleus, and, indeed, could even act cotranscriptionally to remodel 5' cap complex of nascent target mRNAs. Consistent with our findings, previous work has established that eIF4G1 is especially important for cell growth and metastasis of prostate and serous ovarian cancers (Li et al. 2016a; Jaiswal et al. 2018) and selectively controls the translation of a subset of mRNAs encoding DNA repair and cell survival factors (Badura et al. 2012). Moreover, the abnormally elevated levels of eIF4E found in cancer cells were shown to regulate translation of a select set of mRNAs critical for transformation and cancer cell survival, acting through mRNAs with a unique $5^{\prime}$ leader sequence (Truitt et al. 2016). Recent studies have characterized alternative translation pathways that do not depend on mTORC1 or eIF4E (Lee et al. 2016; Shaw et al. 2016). Interestingly, CDK12 expression is regulated by eIF3D rather than eIF4E /de la Parra et al. 2018), which raises the possibility of direct cross-talk between these two translation pathways.

Unexpectedly, genome-wide ribosome profiling also revealed that CDK12 selectively regulates the translation of many critical mitotic regulatory complexes. Consistent with this, CDK12-depleted cells display multiple mitotic defects, including frequent severe chromosome misalignments. CDK12 controls the loading of eIF4G to the mitotic regulatory mRNAs we tested, strongly suggesting that the mechanism involves the phosphorylation and release of 4E-BP1. Moreover, the CDK12 target CHK1 is an important component of the SAC, acting through the Aurora B kinase to prevent formation of lagging chromosomes (Kabeche et al. 2018). Of note, 4E-BP1 proteins phosphorylated at T70 and S65 localize to the mitotic spindle and control spindle assembly in murine oocytes (Cormier 2017; Jansova et al. 2017), which raises the possibility that CDK12 might also act directly at mitotic chromosomes. Consistent with our findings, knockdown of CCNK in prostate cancer cells was previously shown to lead to an Aurora B kinase-dependent mitotic catastrophe, characterized by spindle multipolarity and multinucleation (Schecher et al. 2017). Therefore, the catalytic activity of the CCNK:CDK12 complex is required for multiple steps in mitosis, the loss of which can lead to severe mitotic defects and cancer cell apoptosis.

In summary, we show that CDK12 is the predominant complex responsible for 4E-BP1 phosphorylation at S65 and $\mathrm{T} 70$, and acts in concert with $\mathrm{mTORC} 1$ to control the release of 4E-BP1 and enable binding of eIF4G to a subset of responsive $\mathrm{mRNAs}$ required for mitosis, protein biosynthesis, and the response to DNA damage. These findings highlight a new set of target genes for CDK12, distinct from the $B R C A 1$ and related DNA repair factors that require CDK12 for mRNA biosynthesis (Greenleaf 2018) and intronic polyadenylation (Dubbury et al. 2018). Most strikingly, CDK12 is a part of a novel translation network that ensures the coordinate expression of key factors in centrosome, centromere, and kinetochore proteins to direct mitotic progression. The action of SAC proteins are integrated with the overall response to DNA damage, and 
loss of these factors can lead to defective DNA repair, aneuploidy, and profound genome instability (Janssen et al. 2011; Crasta et al. 2012; Lawrence et al. 2015). Therefore, disruption of the CDK12 translation network likely contributes to the profound genomic instability phenotype that is a hallmark of CDK12 mutant cancers (Chilà et al. 2016; Popova et al. 2016; Menghi et al. 2018; Viswanathan et al. 2018).

\section{Materials and methods}

Cell culture, transfections, DNA damage, immunoblots, and antisera

U2OS cells were obtained from American Type Culture Collection. Cells were confirmed to be free of Mycoplasma infection and cultured in Dulbecco's modified Eagle's medium supplemented with $2 \mathrm{mM}$ L-glutamine and $10 \%$ fetal bovine serum in a $5 \% \mathrm{CO}_{2}$ incubator at $37^{\circ} \mathrm{C}$. The specific siRNAs used in these studies are listed in the Supplemental Material. Following siRNA transfection, DNA damage was induced by incubating the cells in $20 \mu \mathrm{M}$ etoposide or $2 \mathrm{mM}$ HU for $12 \mathrm{~h}$, as indicated in Figure 1. Factor-specific siRNAs were obtained from Life Technologies and were transfected into cells using the Lipofectamine ${ }^{\mathrm{TM}}$ RNAiMAX. Experimental analyses were performed $48 \mathrm{~h}$ after transfection. For negative control siRNA, the Silencer negative control \#1 siRNA was used (Life Technologies).

For immunoblots, cells were lysed in RIPA buffer $(50 \mathrm{mM}$ Tris-Cl at $\mathrm{pH} 7.7,150 \mathrm{mM} \mathrm{NaCl}, 1 \mathrm{mM}$ EDTA, $1 \%$ [v/v] NP$40,0.1 \%[\mathrm{w} / \mathrm{v}]$ SDS, $0.1 \%[\mathrm{w} / \mathrm{v}] \mathrm{NaDeoxycholate})$, and extracts were cleared by centrifugation at $12,000 \mathrm{~g}$ for $15 \mathrm{~min}$ at $4^{\circ} \mathrm{C}$. The supernatants were treated with SDS sample buffer and analyzed by SDS-PAGE and immunoblot. The sources of commercial antisera used for this study are listed in the Supplemental Material.

Reverse transcription and quantitative RT-PCR ( $q R T-P C R$ )

Total RNA was isolated using Trizol (Life Technologies), and reverse transcription was performed using $3 \mu \mathrm{g}$ of total RNA extracted using SuperScript III (Life Technologies) with oligo-dT. PCR measurements of cDNA were performed in triplicate using Power SYBR Green master mixes (Life Technologies). Amplification was carried out in the ABI7300 (Applied Biosystems) with a 10 -min DNA denaturation step at $95^{\circ} \mathrm{C}$ followed by $40 \mathrm{cy}$ cles of $15 \mathrm{sec}$ at $95^{\circ} \mathrm{C}$ and $60 \mathrm{sec}$ at $60^{\circ} \mathrm{C}$. The average of the technical replicates was normalized to GAPDH levels using the comparative CT method. Averages and standard deviation are the result of at least three independent experiments. The qRT-PCR primers used in this manuscript are listed in Supplemental Table S5.

\section{Protein half-life measurements}

To measure the half-life of endogenous Chk1 and p53 proteins, U2OS cells $\left(5 \times 10^{5}\right)$ in a six-well dish were transfected with siRNAs, as indicated in Supplemental Figures S1A,D. After $48 \mathrm{~h}$, cycloheximide (CHX; $50 \mu \mathrm{g} / \mathrm{mL}$ final) was directly added to cells and incubated for the times described in the figure legends. Cells were washed twice with PBS and lysed in RIPA buffer to prepare cell extracts. After centrifugation at $14,000 \mathrm{~g}$ for $15 \mathrm{~min}$ at $4^{\circ} \mathrm{C}$, the soluble fraction was subject to SDS-PAGE and immunoblot analysis. The immunoblot signals were analyzed and quantified by ImageJ to obtain the half-life.

\section{Cytosolic mRNA extraction for $q R T-P C R$}

Subcellular fractionation was carried out at $4^{\circ} \mathrm{C}$ after siRNA transfection for $48 \mathrm{~h}$. Cells were washed and scraped in $1 \mathrm{~mL}$ of ice-cold PBS, centrifuged at centrifugation at $500 \mathrm{~g}$ for $5 \mathrm{~min}$, and resuspended in $1 \mathrm{~mL}$ of buffer A $(10 \mathrm{mM}$ Tris- $\mathrm{HCl}$ at $\mathrm{pH}$ 8.0, $10 \mathrm{mM} \mathrm{KCl}, 1.5 \mathrm{mM} \mathrm{MgCl}_{2}$, protease inhibitors) for $10 \mathrm{~min}$ on ice. After centrifugation at $1500 \mathrm{~g}$ for $5 \mathrm{~min}$, pellets were resuspended in $200 \mu \mathrm{L}$ of buffer B (buffer A plus $0.2 \%$ [v/v] NP-40) and incubated for $5 \mathrm{~min}$ on ice before centrifugation at $5000 \mathrm{~g}$ for 5 min. A supernatant containing the cytosolic fraction and RNA was extracted using acid--phenol:chloroform (pH 4.5) (Invitrogen, AM9720) followed by ethanol precipitation for qRT-PCR.

\section{Analysis of CHK1 mRNA termination efficiency}

For the experiment in Supplemental Figure S1F, U2OS cells $15 \times$ $10^{5}$ ) in a six-well dish were transfected with the indicated siRNAs. After $48 \mathrm{~h}$, total RNA was extracted. The total RNA from each sample $(1 \mu \mathrm{g})$ was subjected to cDNA synthesis with CHK1-specific primers (GSP1; 5'-ACTTCATGAGGCAATTTC TG-3' and GSP2: 5'-AGTGCATGTTAAAGAAGATC-3') using SuperScript III (Life Technologies). qPCR measurements of CHK1 mRNA were performed in triplicate using the SYBR Green master mix (Life Technologies), and the average of the technical replicates was normalized to GAPDH levels using the comparative CT method. The pass-through $(\mathrm{PT})$ ratio represents the percentile of uncleaved mRNA relative to total CHK1 mRNA. Averages and standard deviation are the result of at least three independent experiments.

\section{Metabolic labeling and de novo Chk1 protein synthesis}

Rapidly growing U2OS cells were incubated in methionine-free DMEM for $2 \mathrm{~h}$. L-aziohomoalanine (Click-IT AHA, Thermo Fisher, C10102) was added directly to the medium at a final concentration of $5 \mathrm{mM}$. The cells were incubated for $1 \mathrm{~h}$ to incorporate AHA into newly synthesized proteins. For detection of newly synthesized Chk1 protein from the metabolic labeling, immunoprecipitation was carried out with Chk1 antibody (Santa Cruz Biotechnology, sc-8404) for $12 \mathrm{~h}$. After washing, immunoprecipitates were coupled to biotin conjugates (biotin alkyne; Thermo Fisher, B10185) using the Click-IT protein reaction buffer kit (Thermo Fisher, C10276), and total labeled proteins and immunoprecipitates were detected using the NeutrAvidin horseradish peroxidase conjugate kit (Thermo Fisher, A2664).

\section{Sucrose density gradient sedimentation of polysomes}

To isolate polysomes and associated mRNAs, siRNA-transfected U2OS cells were treated with $100 \mu \mathrm{g} / \mathrm{mL}$ cycloheximide (EMD Millipore) for $10 \mathrm{~min}$ on ice in PBS. Cells were pelleted and lysed in $400 \mathrm{U} / \mathrm{mL}$ fractionation buffer $(10 \mathrm{mM}$ Tris- $\mathrm{HCl}$ at $\mathrm{pH} 8.0,150$ $\mathrm{mM} \mathrm{NaCl}, 1.5 \mathrm{mM} \mathrm{MgCl} 2,0.25 \%$ [v/v] NP-40, 0.1\% Triton-X 100, $10 \mathrm{mM} \mathrm{DTT}, 100 \mu \mathrm{g} / \mathrm{mL}$ cycloheximide, RNasin Plus RNase inhibitor) for $20 \mathrm{~min}$ on ice. Lysates were cleared by centrifugation at $10,000 \mathrm{~g}$ for $10 \mathrm{~min}$, and supernatants were loaded onto the top of stepwise sucrose gradient solutions $11 \mathrm{~mL}$ of each RNase-free $15 \%, 20 \%, 25 \%$ sucrose solution; $0.5 \mathrm{~mL}$ of each $30 \%$, $35 \%, 40 \%$ sucrose solution). The samples were centrifuged in a swinging bucket rotor SW55 Ti (Beckman) at 40,000 rpm for $4 \mathrm{~h}$ at $4^{\circ} \mathrm{C}$ with an acceleration profile of 5 and a deceleration profile of 5. High-molecular-weight polysome fractions were collected from the bottom of the tube and subjected to denaturing RNA agarose gel analysis or acid phenol/chloroform extraction 
followed by qRT-PCR analysis using the primer sets listed in Supplemental Table S5.

Affinity purification of protein kinase complexes and cell-free kinase experiments

Stable HEK293 cell lines that express HA-tagged full-length human CDK12 or Flag-tagged Raptor were established following transfection of expression vectors under puromycin selection at $1 \mathrm{mg} / \mathrm{mL}$ or G418 selection at a final concentration of $500 \mu \mathrm{g} /$ $\mathrm{mL}$, respectively. Cells from five $150-\mathrm{mm}$ dishes were extracted using immunoprecipitation buffer $(50 \mathrm{mM}$ HEPES-NaOH at $\mathrm{pH}$ $7.9,300 \mathrm{mM} \mathrm{NaCl}, 1 \% \mathrm{NP}-40,10 \mathrm{mM} \mathrm{MgCl}_{2}, 15 \%$ glycerol) with protease inhibitors to a final volume of $15 \mathrm{~mL}$ and douncehomogenized. Extracts were clarified by centrifugation at $14,000 \mathrm{~g}$ for $15 \mathrm{~min}$ at $4^{\circ} \mathrm{C}$. Flag-M2 beads (Sigma) or EZview Red anti-HA affinity gel (Sigma) were incubated with the supernatant in a ratio of $80 \mu \mathrm{L}$ of slurry $(50 \%$ beads in slurry) to $6 \mathrm{mg}$ of total protein for $4 \mathrm{~h}$ with rotation at $4^{\circ} \mathrm{C}$. The beads were washed in immunoprecipitation-wash buffer $(25$ mM HEPES$\mathrm{NaOH}$ at $\mathrm{pH} 7.9,300 \mathrm{mM} \mathrm{NaCl}, 0.2 \% \mathrm{NP}-40$ ) a total of four times for $3 \mathrm{~min}$ at $4^{\circ} \mathrm{C}$ and then washed twice in Flag-elution buffer (25 $\mathrm{mM}$ Tris- $\mathrm{HCl}$ at $\mathrm{pH} 7.5,50 \mathrm{mM} \mathrm{NaCl}$ ). Finally, the sample was incubated with $200 \mu \mathrm{g} / \mathrm{mL}$ Flag or HA peptides (Sigma) in 200 $\mu \mathrm{L}$ of elution buffer for $30 \mathrm{~min}$ at room temperature with rotation.

To prepare substrates for the in vitro kinase experiments, the $\mathrm{N}$ terminus of human 4E-BP1 was fused to a GST expression vector to generate a recombinant GST-4E-BP1 protein. After transformation of this vector into Escherichia coli BL21, recombinant 4E$\mathrm{BP} 1$ protein was induced by treatment of IPTG $(0.8 \mu \mathrm{M}$ final), and the soluble protein was purified using glutathione-agarose beads (Thermo Scientific). The purified 4E-BP1 protein was equilibrated in the kinase reaction buffer $(25 \mathrm{mM}$ Tris- $\mathrm{HCl}$ at $\mathrm{pH} 7.5$, $25 \mathrm{mM} \mathrm{KCl}, 5 \mathrm{mM} \mathrm{MgCl}_{2}$ ) to remove any excess glutathione. In vitro phosphorylation reactions contained 50 ng of GST-4E-BP1, $10 \mathrm{ng}$ of CDK12 or Raptor (mTORC1) kinase complex (15 $\mu \mathrm{L}$ of eluate from the affinity purification), or both kinase complexes where indicated in the presence of $100 \mu \mathrm{M}$ ATP, $1 \mathrm{mM}$ DTT, and $5 \mu \mathrm{g} / \mu \mathrm{L}$ BSA in a $50-\mu \mathrm{L}$ final volume of kinase buffer. The reaction was carried out for $30 \mathrm{~min}$ at $25^{\circ} \mathrm{C}$, immediately denatured by boiling with SDS sample buffer, and subjected to immunoblot analysis. To generate point mutations in the GST-4E-BP1 proteins (T37A, T46A, S65A, and T70A) or the kinase-dead fulllength CDK12 (D859A), we used the QuikChange site-directed mutagenesis kit (Agilent), and vectors harboring these mutations were verified by DNA sequencing of individual clones obtained following mutagenesis.

\section{RIP experiments}

All steps were conducted at $4^{\circ} \mathrm{C}$ in RNase-free conditions. U2OS cells $\left(5 \times 10^{6}\right)$ were transfected with the indicated siRNAs and washed twice with cold PBS. Cells were collected in $1.5 \mathrm{~mL}$ of RNA lysis buffer (25 mM Tris- $\mathrm{HCl}$ at $\mathrm{pH} 7.5,150 \mathrm{mM} \mathrm{KCl}$, $5 \mathrm{mM}$ EDTA, $1 \%$ [v/v] NP-40) with freshly added $0.5 \mathrm{mM}$ DTT and $400 \mathrm{U} / \mathrm{mL}$ RNase inhibitor (New England Biolabs) and homogenized by dounce. After centrifugation at $13,000 \mathrm{~g}$ for $20 \mathrm{~min}, 0.7 \mathrm{~mL}$ of clear lysate was transferred to new tubes in addition with antisera ( $5 \mu \mathrm{g}$ per immunoprecipitation) for immunoprecipitation. Antibody and lysate mixtures were incubated overnight with rotation. Aliquots of $60 \mu \mathrm{L}$ of protein A or G (50\% slurry) were added in the mixture and incubated for an additional $2 \mathrm{~h}$. The agarose slurry was collected and washed three times in $1 \mathrm{~mL}$ of RNA lysis buffer followed by centrifugation at $1000 \mathrm{~g}$ for $2 \mathrm{~min}$. After the final wash, $1 \mathrm{~mL}$ of Trizol was used to extract captured RNAs from the immune complexes. After DNA digestion by RNase-free DNase I (New England Biolabs), RNA was precipitated by isopropyl alcohol or concentrated using the RNA Clean and Concentrator kit (Zymo Research). Reverse transcription and qRT-PCR for quantitative RNA analysis was carried out as described above.

RNA-seq and RIP-seq analyses

High-throughput sequencing was performed at the Next-Generation Sequencing Core at The Salk Institute, and statistical analyses were carried out in The Razavi Newman Integrative Genomics and Bioinformatics Core at The Salk Institute. Sequenced reads were quality tested using FASTQC and aligned to the hg19 human genome using the STAR Aligner version 2.4.0 k (Dobin et al. 2013). Mapping was carried out using default parameters (up to 10 mismatches per read and up to nine multimapping locations per read). The genome index was constructed using the gene annotation supplied with the hy19 Illumina iGenomes collection and an overhang value of 100 . Raw gene expression was quantified across all gene exons (RNA-seq) or across gene bodies (RIP-seq), using the top-expressed isoform as proxy for gene expression, and differential gene expression was carried out using the edgeR package version 3.6.8 (Robinson et al. 2010) using biological replicates to compute within-group dispersion. Differentially expressed genes were defined as having a false discovery rate $($ FDR $)<0.05$ and a $\log _{2}$ fold change of $>0.5$ ( $>1.4$-fold or $>0.71$-fold) when comparing two experimental conditions. Genes showing mTOR-specific binding and CDK12-specific binding were defined as those significantly down-regulated in the Rapamycin RIP or siCDK12 RIP compared with the control RIP, while genes that showed mTORspecific or CDK12-specific transcription were defined as those that were significantly altered between control and Rapamycin or siCDK12 total mRNA-seq conditions. The complete list of genes identified by RIP-seq analysis is in Supplemental Table S1.

\section{Annotation and enrichment analyses}

GO term and Kyoto Encyclopedia of Genes and Genomes (KEGG) pathway enrichment analysis and annotation were carried out on gene sets using the HOMER analysis package (Heinz et al. 2010) and the Benjamini and Yekutieli (2001) general correction for multiple testing. Specifically, pathway enrichment analysis was carried out by checking for significant overlap in KEGG, Wikipathways, Reactome, and GO Biological Process databases (database annotations updated November 18, 2015). Motif enrichment analysis was carried out for the region -50 to $150 \mathrm{bp}$ around gene TSS, searching for motif lengths of 8,10 , and 12 or using a set of all vertebrate motifs known to HOMER. Those annotation and enrichment analysis from each RIP-seq and Ribo-seq are summarized in Supplemental Tables S2 and S4, respectively.

Ribo-seq analyses

Preparation of ribosome footprints for Ribo-seq experiments was performed as described Ingolia et al. (2012), with the following modifications. U2OS cells were grown to $\sim 80 \%$ confluency in $15-\mathrm{cm}$ diameter tissue culture dishes. The media was removed, and cells were washed with $5 \mathrm{~mL}$ of ice-cold phosphate-buffered saline (PBS) with $100 \mu \mathrm{g} / \mathrm{mL}$ CHX. Immediately after removing PBS, $400 \mu \mathrm{L}$ of ice-cold lysis buffer $(20 \mathrm{mM}$ Tris- $\mathrm{HCl}$ at $\mathrm{pH} 7.4$, $150 \mathrm{mM} \mathrm{NaCl}, 5 \mathrm{mM} \mathrm{MgCl} 2,1 \%$ Triton X-100) supplemented with $1 \mathrm{mM}$ DTT, $25 \mathrm{U} / \mathrm{mL}$ Turbo DNase (Thermo Fisher, AM2238), and $100 \mu \mathrm{g} / \mathrm{mL}$ CHX was dripped onto the plate. Cells were incubated on ice in lysis buffer for $10 \mathrm{~min}$ with periodic 
vortexing and pipetting to disperse the cells. The lysate was then clarified by centrifugation at $15,000 \mathrm{~g}$ for $10 \mathrm{~min}$. Cell lysates were flash-frozen in liquid nitrogen and stored for up to $5 \mathrm{~d}$ at $-80^{\circ} \mathrm{C}$ prior to ribosome footprinting. The RNA concentrations in lysate were measured using the Qubit broad-range RNA detection assay with $1 \mu \mathrm{L}$ of lysate. For ribosome footprinting, $15 \mathrm{U}$ of TruSeq Nuclease (Illumina) was incubated with $40 \mu \mathrm{g}$ of RNA in $400 \mu \mathrm{L}$ of lysis buffer for $50 \mathrm{~min}$ at room temperature and quenched with 100 U Superase-In RNase I inhibitor (Thermo Fisher) on ice. Following digestion, RPFs were purified from small RNA fragments using MicroSpin S-400 HR columns (GE Life Sciences) according to the Illumina TruSeq Ribo profile kit. RPFs were purified by acid phenol:chloroform extraction followed by isopropanol precipitation. Unfragmented total RNA was extracted from $50 \mu \mathrm{L}$ of cell lysate by acid phenol:chloroform and used to prepare a short read RNA library in parallel with RPF libraries. Ribosomal RNAs were depleted from RPF fragments and total RNA using the Ribo-Zero mammalian kit (Illumina) following the manufacturer's protocol. cDNA sequencing libraries were then prepared using the TruSeq Ribo profile kit (Illumina) following the manufacturer's protocol. Single-end 50 base reads were collected for each library on an Illumina HiSeq2500 with four samples sequenced on a single lane. Two replicates were analyzed for the si-control and si-CDK12-treated U2OS cells.

Ribo-seq and RNA-seq read processing and differential translation analysis by Xtail

Ribo-seq and accompanying total RNA-seq reads were first trimmed of excess $3^{\prime}$ adaptor sequences as described (Ingolia et al. 2012) using the FASTX toolkit. Trimmed Ribo-seq reads aligning to tRNA and rRNA sequences were then removed using STAR version 2.5.2b (Dobin et al. 2013) as described (Wang et al. 2016). Next, the remaining Ribo-seq reads were aligned to the UCSC hg19 human genome assembly containing chromosomes $1-22, \mathrm{X}$, and $\mathrm{Y}$ using the hg19 refGene annotation by STAR. The parameters used for alignment can be found in Calviello et al. (2016). Up to two mismatches were allowed during alignment, and only uniquely mapped reads were kept. Metagene analysis to assess overall Ribo-seq resolution was performed using RibORF (Ji et al. 2015).

Differential translation analysis was conducted using the $\mathrm{R}$ package Xtail version 1.1.5 (Xiao et al. 2016). First, HTSeq-count (Anders et al. 2015) in intersection-strict mode was used to calculate total RNA read counts for hg19 refGene annotations. RPF read counts for the same annotations were calculated using the custom python script in Xiao et al. (2016), which retains only uniquely mapped reads occurring within the middle of the CDS region. Xtail was used to calculate the $\log _{2}$ fold-changes in translation efficiency (TE) between siCDK12 and sicontrol-treated cells from the read count tables. Genes not considered "stable" by Xtail and with a $\log _{2}$ fold change $\geq 1$ or $\leq-1$ were assigned as either "homodirectional," "transcription-only," or "translationonly" category of differential translation. DESeq2 (Love et al. 2014) was also run in parallel with Xtail to calculate differential mRNA expression for hg19 refGene annotations. Plots summarizing the results from both analyses were generated in $\mathrm{R}$. The Ribo-seq results are listed in Supplemental Table S3.

\section{Anchorage-independent colony growth measurement}

Ratla fibroblasts were engineered to express wild-type MYC or vector control with either CDK12 wild-type or CDK12 dominant-negative stable coexpression using G418 and puromycin double selection, as previously described (Cowling et al. 2006).
After $14 \mathrm{~d}$ of plating (1000 cells per well), all colonies (>50 $\mu \mathrm{m})$ or larger colonies $(>200 \mu \mathrm{m})$ in each well were measured and counted using a reticule. Assays were repeated in triplicate wells. Significance was determined using Student's $t$-test.

Immunocytochemistry and image processing

U2OS cells were grown on 12-mm coverslips. Following $48 \mathrm{~h}$ of siRNA transfection, cells were fixed with cold methanol at $-20^{\circ} \mathrm{C}$ for $10 \mathrm{~min}$. Cells were washed with PBS, blocked with $3 \%$ bovine serum albumin (BSA) in $0.1 \%$ PBST $(0.1 \%$ Triton X100 in PBS) for $20 \mathrm{~min}$, and incubated with indicated antibodies for $1.5 \mathrm{~h}$. The cells were washed three times with $0.1 \%$ PBST and then subsequently incubated with Alexa fluor 488 (Invitrogen) or Cy3 conjugate secondary antibodies (Jackson) for $45 \mathrm{~min}$. The cells were washed three times with $0.1 \%$ PBST. The antibodies used in this study were anti- $\alpha$-Tubulin (Sigma, T9026), anti- $\gamma$ Tubulin (Santa Cruz Biotechnology, sc-7396), anti-BubR1 (BD, 612502), and anti-CenpB (Abcam, ab25734). Nuclei were stained with DAPI (Sigma, D9542). The sample coverslips were mounted with Fluoromount-G (Southern Biotech, 0100-01) and imaged in a confocal fluorescence microscope (Zeiss, LSM710) with $0.2 \sim 0.4$ $\mu \mathrm{m}$ thickness of $z$-stack and processed by using ZEN software (Zeiss, ZEN2011) or ImageJ (Fiji, National Institutes of Health) software. The DAPI channel of confocal images was pseudocolored with gray or red for legible chromosome visualization. The tile scanning was performed for objective quantification of mitotic cells with randomly selected $1-\mathrm{mm} \times 1$-mm square areas and 8 $\mu \mathrm{m} z$-stack thickness with 0.5 - $\mu \mathrm{m}$ intervals that covered $>1000$ cells in one image from the siRNA transfected U2OS cells.

\section{Quantification and statistics}

Results are presented as mean \pm SD unless indicated otherwise. Differences were deemed significant when $P<0.05$ in an unpaired Student $t$-test using Prism software (Graphpad Software). At least three independent experiments were performed for imaging analysis followed by quantification or statistical analyses, unless indicated otherwise in the legend.

\section{Acknowledgments}

We thank Dr. Chris Kintner (The Salk Institute) for supporting the confocal imaging studies in his laboratory. S.H.C was supported by the Jean Hahn Hardy Fellowship, Salk Alumni Fellowship, and Pioneer Fund Scholar Awards, and K.A.J. was supported by the Edwin K. Hunter chair. This work was funded by National Institutes of Health (NIH) National Research Service Award (NRSA) F32GM123685 (to T.F.M.), NIH 5R01HD092215 (to S.K.), and NIH R01CA125535 (to K.A.J.).

Author contributions: S.H.C. and K.A.J. were responsible for the experimental design and approach. S.H.C. carried out the biochemical and molecular experiments, including RIP-seq. T.F.M., C.D., and A.S. carried out the ribosome profiling and RNA-seq experiments, including bioinformatics analyses and interpretations. M.N.S. carried out the RIP-seq and RNA-seq studies, including all of the bioinformatics and analyses. S.K. carried out all of the confocal imaging experiments and analyses. S.H.C., T.F.M., S.K., and K.A.J. were involved in writing and editing.

\section{References}

Anders S, Pyl PT, Huber W. 2015. HTSeq-a Python framework to work with high-throughput sequencing data. Bioinformatics 31: 166-169. doi:10.1093/bioinformatics/btu638 
Badura M, Braunstein S, Zavadil J, Schneider RJ. 2012. DNA damage and eIF4G1 in breast cancer cells reprogram translation for survival and DNA repair mRNAs. Proc Natl Acad Sci 109: 18767-18772. doi:10.1073/pnas.1203853109

Bajrami I, Frankum JR, Konde A, Miller RE, Rehman FL, Brough R, Campbell J, Sims D, Rafiq R, Hooper S, et al. 2014. Genome-wide profiling of genetic synthetic lethality identifies CDK 12 as a novel determinant of PARP1/2 inhibitor sensitivity. Cancer Res 74: 287-297. doi:10.1158/0008-5472.CAN-132541

Bartkowiak B, Liu P, Phatnani HP, Fuda NJ, Cooper JJ, Price DH, Adelman K, Lis JT, Greenleaf AL. 2010. CDK12 is a transcription elongation-associated CTD kinase, the metazoan ortho$\log$ of yeast Ctk1. Genes Dev 24: 2303-2316. doi:10.1101/ gad.1968210

Benjamini Y, Yekutieli D. 2001. The control of the false discovery rate in multiple testing under dependency. Ann Stat 29: 11651188. doi:10.1214/aos/1013699998

Biffo S, Manfrini N, Ricciardi S. 2018. Crosstalks between translation and metabolism in cancer. Curr Opin Genet Dev 48: 75-81. doi:10.1016/j.gde.2017.10.011

Blazek D, Kohoutek J, Bartholomeeusen K, Johansen E, Hulinkova P, Luo Z, Cimermancic P, Ule J, Peterlin BM. 2011. The Cyclin K/Cdk12 complex maintains genomic stability via regulation of expression of DNA damage response genes. Genes Dev 25: 2158-2172. doi:10.1101/gad.16962311

Borden KL. 2016. The eukaryotic translation initiation factor eIF4E wears a 'cap' for many occasions. Translation 4: e1220899. doi:10.1080/21690731.2016.1220899

Bowman EA, Kelly WG. 2014. RNA polymerase II transcription elongation and Pol II CTD Ser2 phosphorylation: a tail of two kinases. Nucleus 5: 224-236. doi:10.4161/nucl .29347

Calviello L, Mukherjee N, Wyler E, Zauber H, Hirsekorn A, Selbach M, Landthaler M, Obermayer B, Ohler U. 2016. Detecting actively translated open reading frames in ribosome profiling data. Nat Methods 13: 165-170. doi:10.1038/nmeth .3688

Cheng SW, Kuzyk MA, Moradian A, Ichu TA, Chang VC, Tien JF, Vollett SE, Griffith M, Marra MA, Morin GB. 2012. Interaction of cyclin-dependent kinase 12/CrkRS with cyclin K1 is required for the phosphorylation of the C-terminal domain of RNA polymerase II. Mol Cell Biol 32: 4691-4704. doi:10 .1128/MCB.06267-11

Chilà R, Guffanti F, Damia G. 2016. Role and therapeutic potential of CDK12 in human cancers. Cancer Treat Rev 50: 83-88. doi:10.1016/j.ctrv.2016.09.003

Coordes B, Brünger KM, Burger K, Soufi B, Horenk J, Eick D, Olsen JV, Sträßer K. 2015. Ctk1 function is necessary for full translation initiation activity in Saccharomyces cerevisiae. Eukaryot Cell 14: 86-95. doi:10.1128/EC.00106-14

Cormier P. 2017. Translation regulator ballet in meiotic spindle. Cell Cycle 16: 733-734. doi:10.1080/15384101.2017 .1304732

Cowling VH, Chandriani S, Whitfield ML, Cole MD. 2006. A conserved Myc protein domain, MBIV, regulates DNA binding, apoptosis, transformation, and G2 arrest. Mol Cell Biol 26: 4226-4239. doi:10.1128/MCB.01959-05

Crasta K, Ganem NJ, Dagher R, Lantermann AB, Ivanova EV, Pan Y, Nezi L, Protopopov A, Chowdhury D, Pellman D. 2012. DNA breaks and chromosome pulverization from errors in mitosis. Nature 482: 53-58. doi:10.1038/nature 10802

Dai Q, Lei T, Zhao C, Zhong J, Tang YZ, Chen B, Yang J, Li C, Wang S, Song X, et al. 2012. Cyclin K-containing kinase complexes maintain self-renewal in murine embryonic stem cells. J Biol Chem 287: 25344-25352. doi:10.1074/jbc.M111 .321760

Davidson L, Muniz L, West S. 2014. 3' end formation of premRNA and phosphorylation of Ser2 on the RNA polymerase II CTD are reciprocally coupled in human cells. Genes Dev 28: 342-356. doi:10.1101/gad.231274.113

de la Parra C, Ernlund A, Alard A, Ruggles K, Ueberheide B, Schneider RJ. 2018. A widespread alternate form of cap-dependent mRNA translation initiation. Nat Commun 9: 3068. doi:10.1038/s41467-018-05539-0

Dobin A, Davis CA, Schlesinger F, Drenkow J, Zaleski C, Jha S, Batut P, Chaisson M, Gingeras TR. 2013. STAR: ultrafast universal RNA-seq aligner. Bioinformatics 29: 15-21. doi:10 $.1093 /$ bioinformatics/bts635

Dubbury SJ, Boutz PL, Sharp PA. 2018. CDK12 regulates DNA repair genes by suppressing intronic polyadenylation. Nature 564: 141-145. doi:10.1038/s41586-018-0758-y

Eick D, Geyer M. 2013. The RNA polymerase II carboxy-terminal domain (CTD) code. Chem Rev 113: 8456-8490. doi:10.1021/ cr400071f

Eifler TT, Shao W, Bartholomeeusen K, Fujinaga K, Jäger S, Johnson JR, Luo Z, Krogan NJ, Peterlin BM. 2015. Cyclin-dependent kinase 12 increases $3^{\prime}$ end processing of growth factorinduced c-FOS transcripts. Mol Cell Biol 35: 468-478. doi:10 $.1128 /$ MCB.01157-14

Ekumi KM, Paculova H, Lenasi T, Pospichalova V, Bösken CA, Rybarikova J, Bryja V, Geyer M, Blazek D, Barboric M. 2015. Ovarian carcinoma CDK12 mutations misregulate expression of DNA repair genes via deficient formation and function of the Cdk12/CycK complex. Nucleic Acids Res 43: 25752589. doi:10.1093/nar/gkv101

Gingras AC, Gygi SP, Raught B, Polakiewicz RD, Abraham RT, Hoekstra MF, Aebersold R, Sonenberg N. 1999. Regulation of 4E-BP1 phosphorylation: a novel two-step mechanism. Genes Dev 13: 1422-1437. doi:10.1101/gad.13.11.1422

Gingras AC, Raught B, Gygi SP, Niedzwiecka A, Miron M, Burley SK, Polakiewicz RD, Wyslouch-Cieszynska A, Aebersold R, Sonenberg N. 2001. Hierarchical phosphorylation of the translation inhibitor 4E-BP1. Genes Dev 15: 2852-2864. doi:10 $.1101 / \operatorname{gad} .887201$

Greenleaf AL. 2018. Human CDK12 and CDK13, multi-tasking CTD kinases for the new millenium. Transcription 14: 1-20. doi:10.1080/21541264.2018.1535211

Harlen KM, Churchman LS. 2017. The code and beyond: transcription regulation by the RNA polymerase II carboxy-terminal domain. Nat Rev Mol Cell Biol 18: 263-273. doi:10.1038/ nrm.2017.10

Heinz S, Benner C, Spann N, Bertolino E, Lin YC, Laslo P, Cheng IX, Murre C, Singh H, Glass CK. 2010. Simple combinations of lineage-determining transcription factors prime cis-regulatory elements required for macrophage and B cell identities. Mol Cell 38: 576-589. doi:10.1016/j.molcel.2010 .05 .004

Hsin JP, Manley JL. 2012. The RNA polymerase II CTD coordinates transcription and RNA processing. Genes Dev 26: 2119-2137. doi:10.1101/gad.200303.112

Ingolia NT. 2016. Ribosome footprint profiling of translation throughout the genome. Cell 165: 22-33. doi:10.1016/j.cell .2016.02.066

Ingolia NT, Brar GA, Rouskin S, McGeachy AM, Weissman JS. 2012. The ribosome profiling strategy for monitoring translation in vivo by deep sequencing of ribosome-protected mRNA fragments. Nat Protoc 7: 1534-1550. doi:10.1038/nprot.2012 .086 
Jaiswal PK, Koul S, Shanmugam PST, Koul HK. 2018. Eukaryotic translation initiation factor $4 \gamma 1$ (eIF4G1) is upregulated during Prostate cancer progression and modulates cell growth and metastasis. Sci Rep 8: 7459. doi:10.1038/s41598-01825798-7

Jansova D, Koncicka M, Tetkova A, Cerna R, Malik R, Del Llano E, Kubelka M, Susor A. 2017. Regulation of 4E-BP1 activity in the mammalian oocyte. Cell Cycle 16: 927-939. doi:10.1080/ 15384101.2017.1295178

Janssen A, van der Burg M, Szuhai K, Kops GJ, Medema RH. 2011. Chromosome segregation errors as a cause of DNA damage and structural chromosome aberrations. Science 333: 18951898. doi:10.1126/science.1210214

Ji Z, Song R, Regev A, Struhl K. 2015. Many lncRNAs, 5'UTRs, and pseudogenes are translated and some are likely to express functional proteins. Elife 4: e08890. doi:10.7554/ eLife.08890

Jonkers I, Lis JT. 2015. Getting up to speed with transcription elongation by RNA polymerase II. Nat Rev Mol Cell Biol 16: 167-177. doi:10.1038/nrm3953

Joshi PM, Sutor SL, Huntoon CJ, Karnitz LM. 2014. Ovarian cancer-associated mutations disable catalytic activity of CDK12, a kinase that promotes homologous recombination repair and resistance to cisplatin and poly(ADP-ribose) polymerase inhibitors. J Biol Chem 289: 9247-9253. doi:10.1074/jbc.M114 .551143

Juan HC, Lin Y, Chen HR, Fann MJ. 2016. Cdk12 is essential for embryonic development and the maintenance of genomic stability. Cell Death Differ 23: 1038-1048. doi:10.1038/cdd .2015 .157

Kabeche L, Nguyen HD, Buisson R, Zou L. 2018. A mitosis-specific and R loop-driven ATR pathway promotes faithful chromosome segregation. Science 359: 108-114. doi:10.1126/science .aan6490

Kang SA, Pacold ME, Cervantes CL, Lim D, Lou HJ, Ottina K, Gray NS, Turk BE, Yaffe MB, Sabatini DM. 2013. mTORC1 phosphorylation sites encode their sensitivity to starvation and rapamycin. Science 341: 1236566. doi:10.1126/science .1236566

Kapanidou M, Lee S, Bolanos-Garcia VM. 2015. BubR1 kinase: protection against aneuploidy and premature aging. Trends Mol Med 21: 364-372. doi:10.1016/j.molmed.2015.04 .003

Lawrence KS, Chau T, Engebrecht J. 2015. DNA damage response and spindle assembly checkpoint function throughout the cell cycle to ensure genomic integrity. PLoS Genet 11: e1005150. doi:10.1371/journal.pgen.1005150

Lee AS, Kranzusch PJ, Doudna JA, Cate JH. 2016. eIF3d is an mRNA cap-binding protein that is required for specialized translation initiation. Nature 536: 96-99. doi:10.1038/ nature 18954

Lei T, Zhang P, Zhang X, Xiao X, Zhang J, Qiu T, Dai Q, Zhang Y, Min L, Li Q, et al. 2018. Cyclin K regulates prereplicative complex assembly to promote mammalian cell proliferation. Nat Commun 9: 1876. doi:10.1038/s41467-018-04258-w

Li L, Luo Q, Xie Z, Li G, Mao C, Liu Y, Wen X, Yin N, Cao J, Wang J, et al. 2016a. Characterization of the expression of the RNA binding protein eIF4G1 and its clinicopathological correlation with serous ovarian cancer. PLoS One 11: e0163447. doi:10 .1371/journal.pone.0163447

Li X, Chatterjee N, Spirohn K, Boutros M, Bohmann D. 2016b. Cdk12 Is a gene-selective RNA polymerase II kinase that regulates a subset of the transcriptome, including Nrf2 target genes. Sci Rep 6: 21455. doi:10.1038/srep21455
Liang K, Gao X, Gilmore JM, Florens L, Washburn MP, Smith E, Shilatifard A. 2015. Characterization of human cyclin-dependent kinase 12 (CDK12) and CDK13 complexes in C-terminal domain phosphorylation, gene transcription, and RNA processing. Mol Cell Biol 35: 928-938. doi:10.1128/MCB .01426-14

Love MI, Huber W, Anders S. 2014. Moderated estimation of fold change and dispersion for RNA-seq data with DESeq2. Genome Biol 15: 550. doi:10.1186/s13059-014-0550-8

Matt S, Hofmann TG. 2016. The DNA damage-induced cell death response: a roadmap to kill cancer cells. Cell Mol Life Sci 73: 2829-2850. doi:10.1007/s00018-016-2130-4

Menghi F, Barthel FP, Yadav V, Tang M, Ji B, Tang Z, Carter GW, Ruan Y, Scully R, Verhaak RGW, et al. 2018. The tandem duplicator phenotype is a prevalent genome-wide cancer configuration driven by distinct gene mutations. Cancer Cell 34: 197-210.e195. doi:10.1016/j.ccell.2018.06.008

Mertins P, Mani DR, Ruggles KV, Gillette MA, Clauser KR, Wang P, Wang X, Qiao JW, Cao S, Petralia F, et al. 2016. Proteogenomics connects somatic mutations to signalling in breast cancer. Nature 534: 55-62. doi:10.1038/nature 18003

Morita M, Gravel SP, Hulea L, Larsson O, Pollak M, St-Pierre J, Topisirovic I. 2015. mTOR coordinates protein synthesis, mitochondrial activity and proliferation. Cell Cycle 14: 473-480. doi:10.4161/15384101.2014.991572

Musacchio A. 2015. The molecular biology of spindle assembly checkpoint signaling dynamics. Curr Biol 25: R1002-1018. doi:10.1016/j.cub.2015.08.051

Osborne MJ, Borden KL. 2015. The eukaryotic translation initiation factor eIF4E in the nucleus: taking the road less traveled. Immunol Rev 263: 210-223. doi:10.1111/imr .12240

Popova T, Manié E, Boeva V, Battistella A, Goundiam O, Smith NK, Mueller CR, Raynal V, Mariani O, Sastre-Garau X, et al. 2016. Ovarian cancers harboring inactivating mutations in CDK12 display a distinct genomic instability pattern characterized by large tandem duplications. Cancer Res 76: 18821891. doi:10.1158/0008-5472.CAN-15-2128

Pourdehnad M, Truitt ML, Siddiqi IN, Ducker GS, Shokat KM, Ruggero D. 2013. Myc and mTOR converge on a common node in protein synthesis control that confers synthetic lethality in Myc-driven cancers. Proc Natl Acad Sci 110: 11988-11993. doi:10.1073/pnas.1310230110

Qin X, Jiang B, Zhang Y. 2016. 4E-BP1, a multifactor regulated multifunctional protein. Cell Cycle 15: 781-786. doi:10 $.1080 / 15384101.2016 .1151581$

Robinson MD, McCarthy DJ, Smyth GK. 2010. edgeR: a Bioconductor package for differential expression analysis of digital gene expression data. Bioinformatics 26: 139-140. doi:10 $.1093 /$ bioinformatics/btp616

Röther S, Sträßer K. 2007. The RNA polymerase II CTD kinase Ctk1 functions in translation elongation. Genes Dev 21: 1409-1421. doi:10.1101/gad.428407

Saxton RA, Sabatini DM. 2017. mTOR signaling in growth, metabolism and disease. Cell 168: 960-976. doi:10.1016/j.cell .2017.02.004

Schecher S, Walter B, Falkenstein M, Macher-Goeppinger S, Stenzel P, Krümpelmann K, Hadaschik B, Perner S, Kristiansen G, Duensing S, et al. 2017. Cyclin K dependent regulation of Aurora $\mathrm{B}$ affects apoptosis and proliferation by induction of mitotic catastrophe in prostate cancer. Intl J Cancer 141: 16431653. doi:10.1002/ijc.30864

Shah M, Su D, Scheliga JS, Pluskal T, Boronat S, Motamedchaboki K, Campos AR, Qi F, Hidalgo E, Yanagida M, et al. 
2016. A transcript-specific eIF3 complex mediates global translational control of energy metabolism. Cell Rep 16: 1891-1902. doi:10.1016/j.celrep.2016.07.006

Tame MA, Raaijmakers JA, Afanasyev P, Medema RH. 2016. Chromosome misalignments induce spindle-positioning defects. $E M B O$ Rep 17: 317-325. doi:10.15252/embr.201541 143

Thoreen CC. 2017. The molecular basis of mTORC1-regulated translation. Biochem Soc Trans 45: 213-221. doi:10.1042/ BST20160072

Truitt ML, Conn CS, Shi Z, Pang X, Tokuyasha T, Coady AM, Seo Y, Barna M, Ruggero D. 2016. Differential requirements for eIF4E dose in normal development and cancer. Cell 162: 5971. doi:10.1016/j.cell.2015.05.049

van Riggelen J, Yetil A, Felsher DW. 2010. MYC as a regulator of ribosome biogenesis and protein synthesis. Nat Rev Cancer 10: 301-309. doi:10.1038/nrc2819

Viswanathan SR, Ha G, Hoff AM, Wala JA, Carrot-Zhang J, Whelan CW, Haradhvala NJ, Freeman SS, Reed SC, Rhoades J, et al. 2018. Structural alterations driving castrationresistant prostate cancer revealed by linked-read genome se- quencing. Cell 174: 433-447.e419. doi:10.1016/j.cell.2018.05 .036

Wang H, McManus J, Kingsford C. 2016. Isoform-level ribosome occupancy estimation guided by transcript abundance with Ribomap. Bioinformatics 32: 1880-1882. doi:10.1093/bioinfor matics/btw085

Wu YM, Cieślik M, Lonigro RJ, Vats P, Reimers MA, Cao X, Ning Y, Wang L, Kunju LP, de Sarkar N, et al. 2018. Inactivation of CDK12 delineates a distinct immunogenic class of advanced prostate cancer. Cell 173: 1770-1782. doi:10.1016/j.cell.2018 .04 .034

Xiao Z, Zou Q, Liu Y, Yang X. 2016. Genome-wide assessment of differential translations with ribosome profiling data. Nat Commun 7: 11194. doi:10.1038/ncomms11194

Zhang Y, Yang L, Kucherlapati M, Chen F, Hadjipanayis A, Pantazi A, Bristow CA, Lee EA, Mahadeshwar HS, Tang J, et al. 2018. A pan-cancer compendium of genes deregulated by somatic genomic rearrangement across more than 1,400 cases. Cell Rep 24: 515-527. doi:10.1016/j.celrep.2018.06 .025 


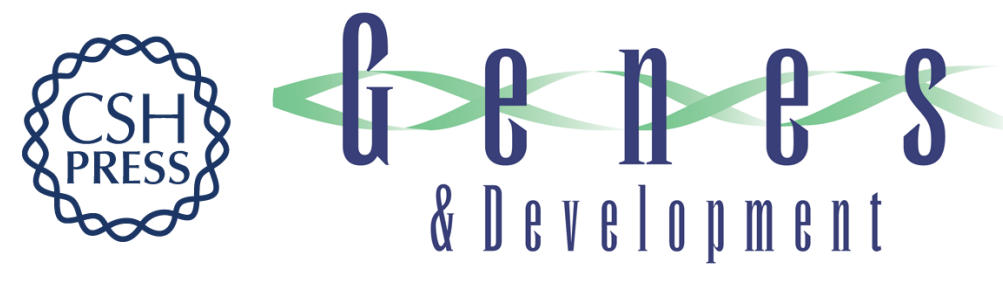

\section{CDK12 phosphorylates 4E-BP1 to enable mTORC1-dependent translation and mitotic genome stability}

Seung H. Choi, Thomas F. Martinez, Seongjae Kim, et al.

Genes Dev. 2019, 33: originally published online February 28, 2019

Access the most recent version at doi:10.1101/gad.322339.118

\section{Supplemental http://genesdev.cshlp.org/content/suppl/2019/02/28/gad.322339.118.DC1 Material}

References This article cites 72 articles, 23 of which can be accessed free at: http://genesdev.cshlp.org/content/33/7-8/418.full.html\#ref-list-1

Creative This article is distributed exclusively by Cold Spring Harbor Laboratory Press for the first Commons six months after the full-issue publication date (see

License http://genesdev.cshlp.org/site/misc/terms.xhtml). After six months, it is available under a Creative Commons License (Attribution-NonCommercial 4.0 International), as described at http://creativecommons.org/licenses/by-nc/4.0/.

Email Alerting Receive free email alerts when new articles cite this article - sign up in the box at the top Service right corner of the article or click here.

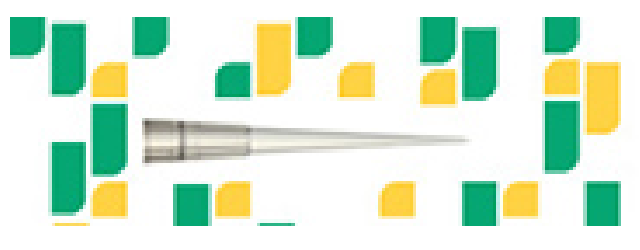

Focused on your science. 